\title{
Elevated Flat Floor Depressions in the Southern Highlands of Mars
}

\author{
Adam James Benthem \\ McBain, Michigan \\ Bachelor of Science, Calvin College, 2004 \\ A Thesis presented to the Graduate Faculty \\ of the University of Virginia in Candidacy for the Degree of \\ Master of Science \\ Department of Environmental Science \\ University of Virginia \\ December, 2009
}




\section{Abstract:}

Recent missions to Mars have produced a $<18 \mathrm{~m} /$ pixel image coverage over significant portions of the planet's surface allowing systematic investigations of many meter-to-decimeterscale features which were previously irresolvable. Utilizing images from MOC, HiRISE, CTX, THEMIS VIS, and HRSC orbiting imaging systems I have identified a latitude-dependent type of depression found on the rims of many craters here in referred to as Elevated Flat Floor Depressions (EFFDs). A detailed survey of these features was conducted across the Southern Highlands of Mars. I have found that EFFDs are characterized by: 1) A distinctive morphology. EFFDs are approximately $1000 \mathrm{~m}$ in diameter, orientated parallel to the crater rim, and have well defined steep bounding scarps with flat floors and lacking evidence of surfical fluvial or creep related inputs or outputs of sediment, resulting in conspicuous volume loss. 2) A restricted geographic range. EFFDs are located in a latitude band between $30^{\circ}$ and $60^{\circ}$ in both hemispheres and are situated near the apex of crater rims. EFFDs decrease in frequency and change their axial orientation relative to their distance from the crater rim. 3) EFFDs are recent formations, likely Amazonian in age (<1.8 Ga bp). EFFDs have a "fresh" appearance with steep scarps and evidence of recent backwasting. As these features are superimposed on highly eroded terrains they must be formed by relatively recent landform modification and post-date crater formation and the Noachian fluvial period.

I conclude that EFFDs morphology, latitude dependence, and volume loss is most consistent with periglacial processes similar to terrestrial thermokarst depressions. I propose that crater rims, as high erosional environments with strong winds and steep slopes, create conditions in which a protective cover is removed preferentially and a subsurface layer composed of an ice and dust mixture is exposed and sublimates into the atmosphere. 


\section{Acknowledgements:}

I would first like to acknowledge my research advisor, Alan Howard, for patiently answering my questions as I wandered around scratching my head about this project. I would also like to thank Meredith Higbee and Yo Matsubara for listening and helping me talk through my ideas. Special thanks to NASA and the whole Mars community for making hundreds of millions of dollars worth of data easily and readily available. To my family, thank you for smiling and nodding when I complained about work. And finally, thank you to all my friends down here in Charlottesville. I had an amazing time and wouldn't trade it for the world. 


\section{Table of Contents}

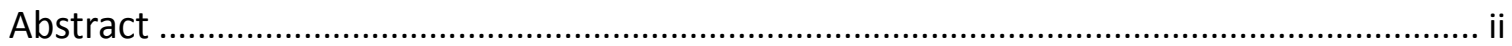

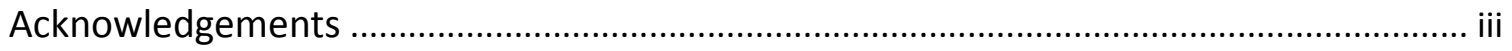

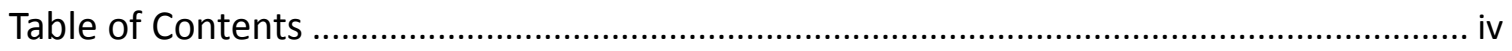

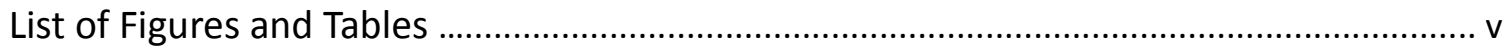

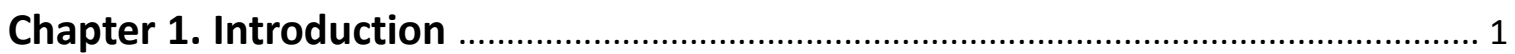

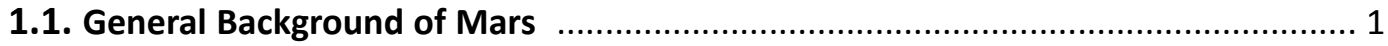

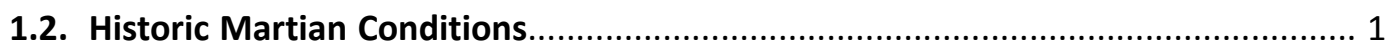

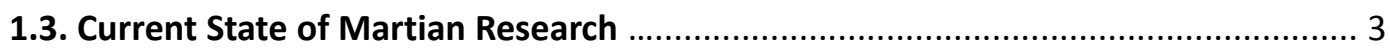

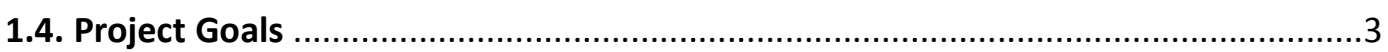

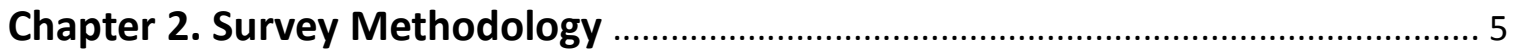

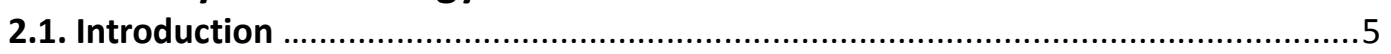

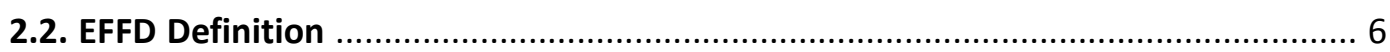

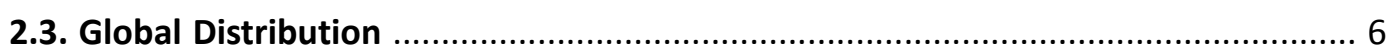

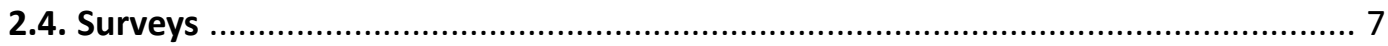

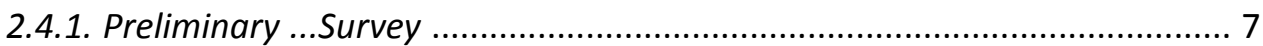

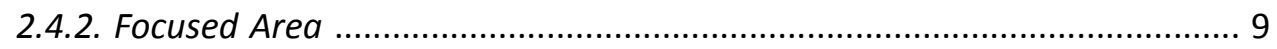

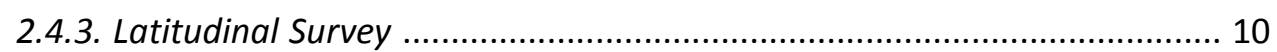

2.4.4. High Resolution Survey ....................................................................... 10

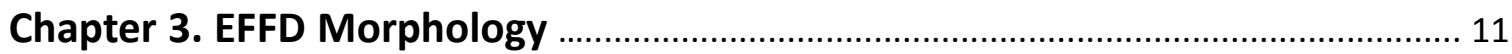

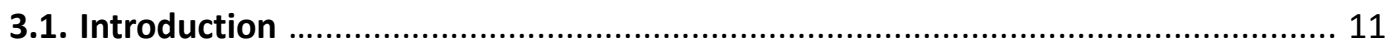

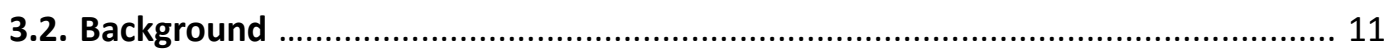

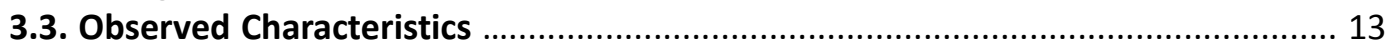

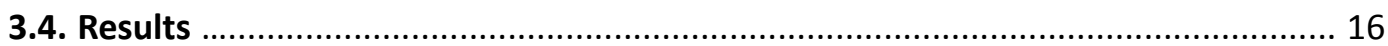

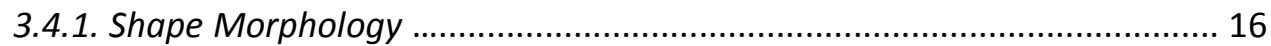

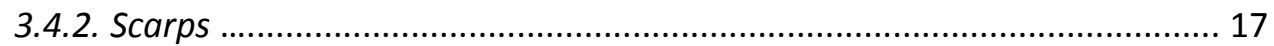

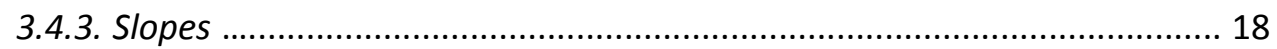

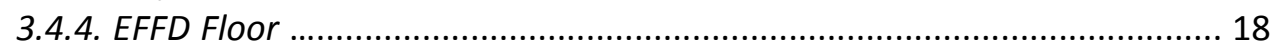

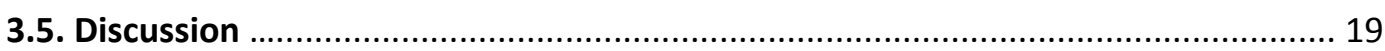

Chapter 4. Regional Landscape and Global Distribution ..................................... 23

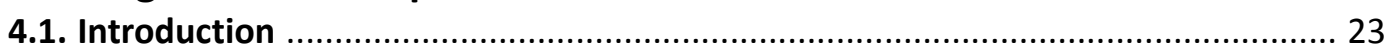

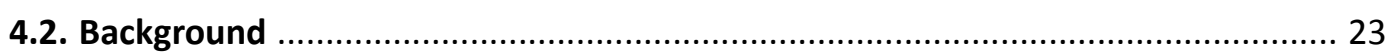

4.2.1. Current Conditions in the Mid-Latitudes ............................................... 23

4.2.2. Historical Conditions in the Mid-Latitudes ............................................. 24

4.2.3. Planetary Climate and Hydrological Cycle ............................................ 25

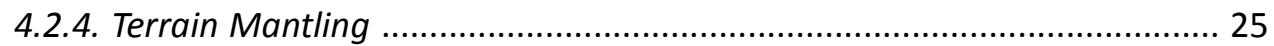

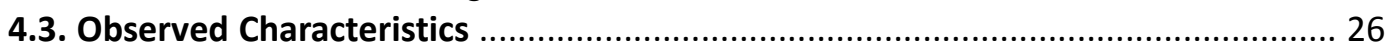

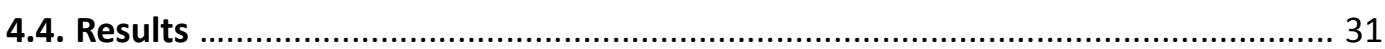

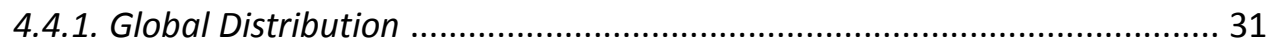




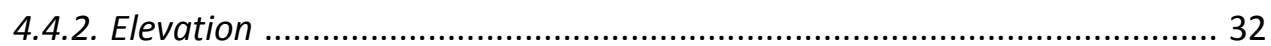

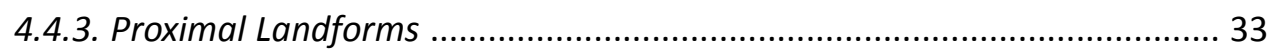

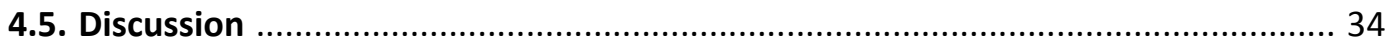

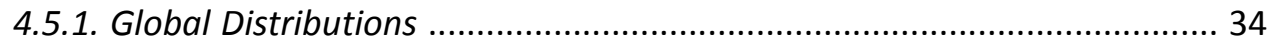

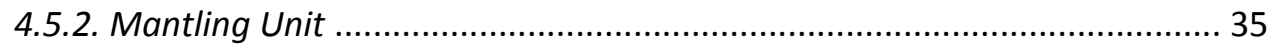

Chapter 5. Influence of Crater Morphology ............................................................ 36

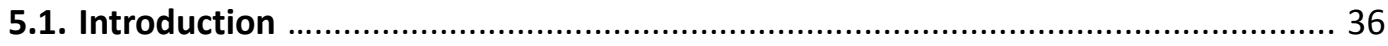

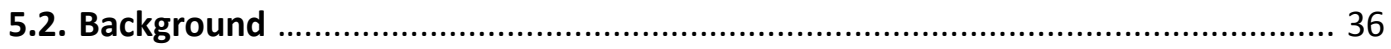

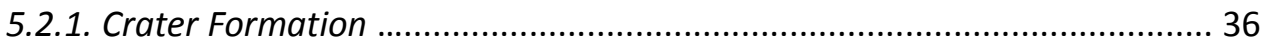

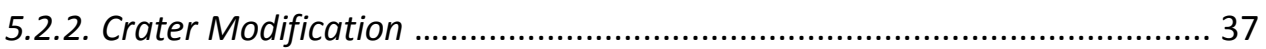

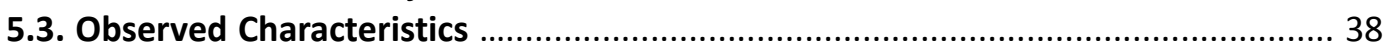

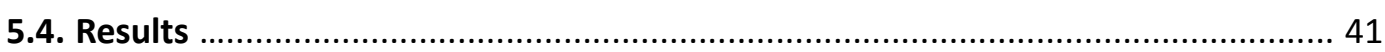

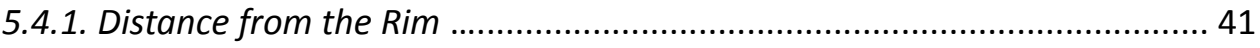

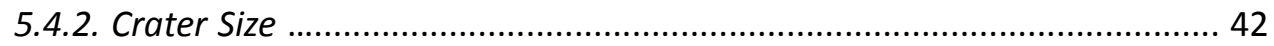

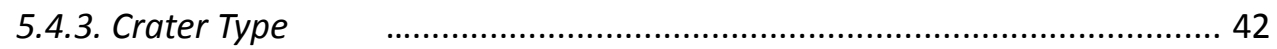

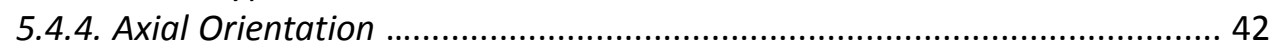

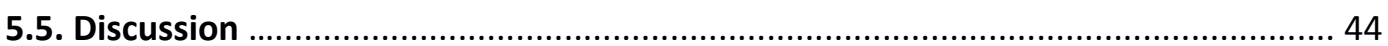

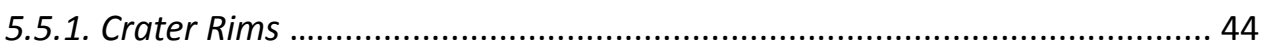

5.5.2. Other Crater Properties ...................................................................... 46

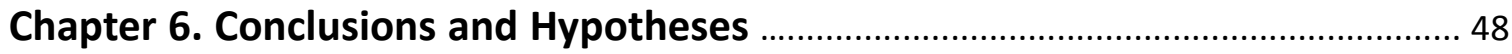

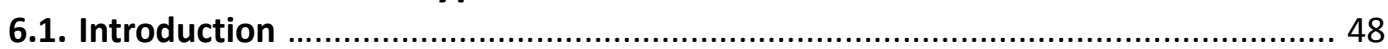

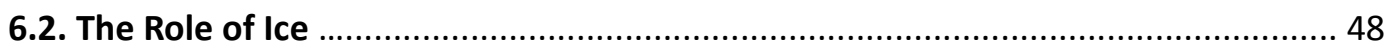

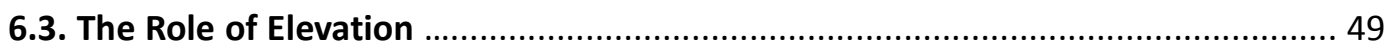

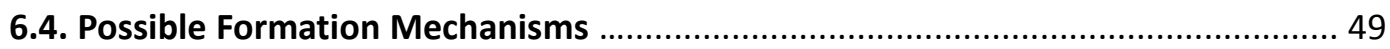

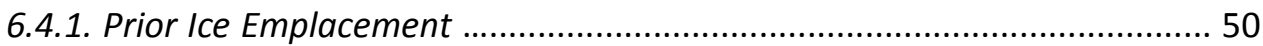

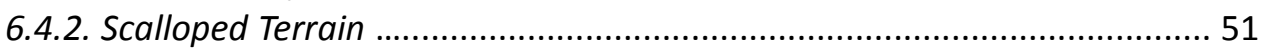

6.4.3. Elevationally Triggered Sublimation ....................................................... 52

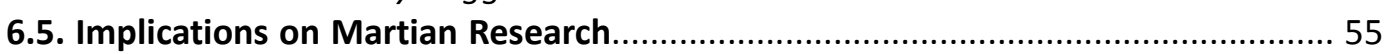

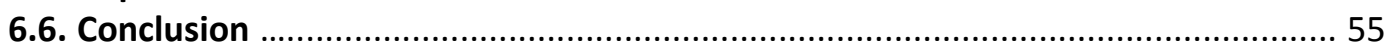

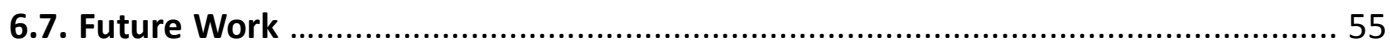

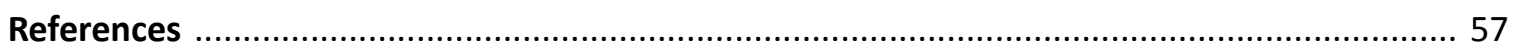




\section{List of Figures and Tables}

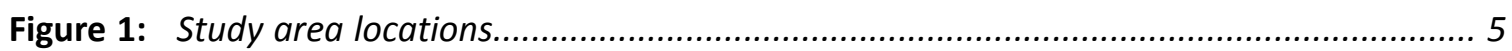

Figure 2: Elevated Flat Floor Depression(EFFD) ............................................................... 7

Figure 3: Types of enclosed depressions on Mars.............................................................. 12

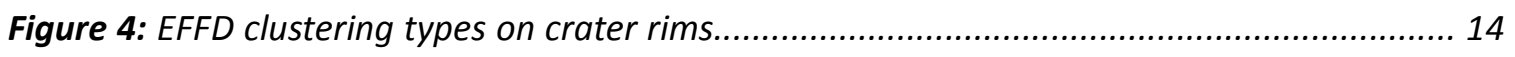

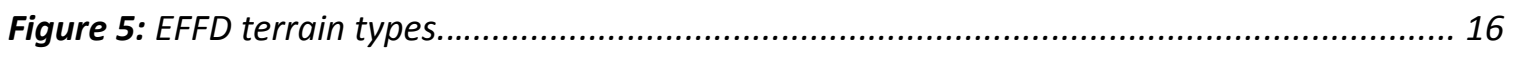

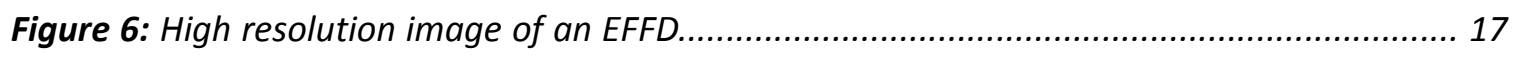

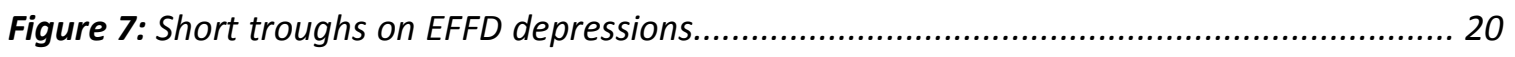

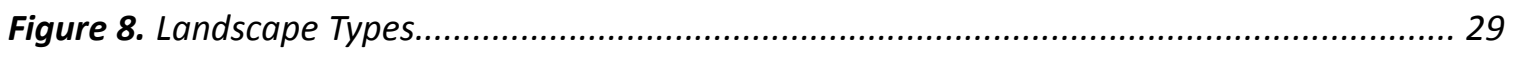

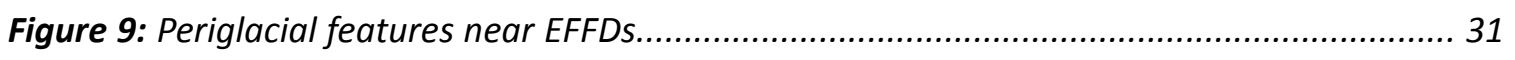

Figure 10: EFFDs distribution relative to ground ice features................................................. 32

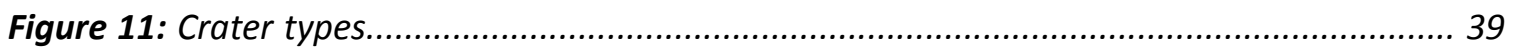

Figure 12: EFFD distribution on craters....................................................................................... 41

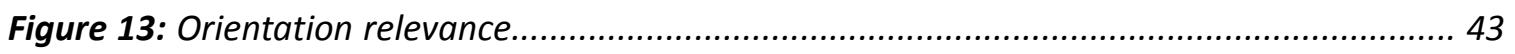

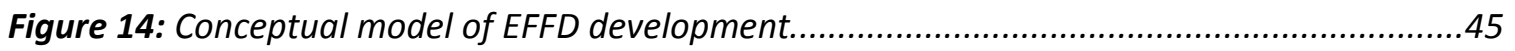




\section{INTRODUCTION}

\subsection{General Background of Mars}

Since antiquity Mars has captured the imagination of humanity and has been seen as our little brother in our solar system. From Giovanni Schiaparelli, who suggested that there were canals built on the Mars, to the cartoon character Marvin the Martian, Mars has been seen as an "almost Earth" that is similar in some aspects, but radically different in others. Since 1960, 43 missions to Mars have been conducted by 6 countries driven by the search for life, habitability, and our desire to explore and learn.

The main objective behind much of the exploration of Mars is the search for water. From astrobiology to atmospheric dynamics to surface morphology, water is the driving force, both in the past and present, which shapes the planet. However, the role of water on Mars is not well understood and remains the largest controversy concerning Mars. Mars contains a diverse and unique set of landforms representing multiple environmental regimes and records the history of a planet that has undergone radical changes since its formation. The historical evidence and role of liquid water on Mars has long been the focus of vigorous debate as water in its liquid, solid and vapor phases creates physical constraints on the possible temperature, climatic and atmospheric conditions that have operated on the planet.

\subsection{Historic Martian Conditions}

Currently, Mars is a cold, dry desert with atmospheric conditions too cold and thin to support long term stability of liquid water at the surface or even exposed ice except in polar regions, but the evidence of past water and ice is abundant. Valley networks, overflowing lakes, 
and ice related features all indicate a hydrologically active planet [Fassett 2008, Mahaney et. al. 2007, Soare et. al. 2007, Page 2006, Head et. al. 2005, Li et. al. 2005 Costard and Baker 2001, Rossbacher and Judson 1981, Wade and De Wys 1968].

With Mars a hundred million kilometers from earth, most of our information about the planet is derived from satellite imagery, remote sensing data, and examining Earth analogs. We do know that with a current average temperature of $212 \mathrm{~K}$ and atmospheric pressure of 3-7 mbars, water is not stable on the surface of Mars and most of the observed water related features on the planet could not have been formed under current conditions [Kasting 1991]. And with astronomical data indicating that the sun's luminosity used to be $30 \%$ less than it is currently [Kasting 1991], the past pressure and atmospheric composition must have been significantly different for liquid water to have ever played a role. For many scientists, these requirements lead to strong reluctance to accept that precipitation ever occurred on the Martian surface, believing instead that the water related features result from hydrothermally-driven processes [Squyres 1992, Gulick 2001]. Most recent researchers, however, believe that direct precipitation is necessary to account for the physical evidence of crater overflow, integrated drainages, and the extent of fluvial features [Fassett 2008, Ansan and Mangold 2006, Howard et. al. 2005, Quantin et. al. 2005, Forsberg-Taylor et. al. 2004, Moore and Howard 2003, Craddock and Howard 2002, Irwin et. al. 2002, Forget et. al. 1997]. So where is this water? To reconcile the historical evidence of water and the current dryness of the planet many have suggested that much of the water is tied up in the cryosphere in the ground and models suggest that ground ice is currently stable in the near surface at latitudes poleward of $30^{\circ}$ [Mellon and Feldman 2004, Fanale et. al. 1986]. Recent measurements have shown that ground ice and ice rich soils may currently be present poleward of $40^{\circ}$ [Mellon and Feldman 2004, Boynton et. al. 2002, Mustard et. al. 2001] and seasonal surface frosting occurs poleward of $24^{\circ}$ [Schorghofer 2006]. 


\subsection{Current State of Martian Research}

To understand the development of Martian history, morphology, and resource distribution it is important to identify and investigate diagnostic surface features and to assess their formative processes and environments.

Recently, with the deployment of the Mars Global Surveyor, Mars Odyssey, and Mars Reconnaissance Orbiter missions, high resolution imagery has become available across large portions of Mars creating a global coverage at $\sim 100 \mathrm{~m} /$ pixel and significant coverage at $<5 \mathrm{~m} /$ pixel. From these images many unique small scale features have been identified [Page 2007, Caprarelli et. al. 2007, Cord et. al. 2007, Bourke et. al. 2008] that previously were irresolvable and have helped increase our understanding of the physical processes that operated on Mars. As both the resolution and coverage of high resolution imagery expands, the identification and documentation of new and diagnostic features will allow us to refine our understanding of the historic processes and environmental conditions which have shaped Mars as well as to investigate those that operate today.

\subsection{Project Goals}

My study focuses on a previously undescribed, hundred-meter-scale, irregularly shaped depression type located on crater rims in the southern mid latitudes which I have termed Elevated Flat Floor Depressions (EFFDs) (Figure 2). I chose to study this feature for my thesis as it appeared to be a late stage modification of the landscape and present an intriguing morphologic puzzle of explaining how an enclosed depression can form on the top of a mountain. The goal of this project was to document, characterize, classify, and assess these depressions and identify their formative process and associated climatic conditions. 
This study focuses on EFFDs in three contexts; their global distribution, their relationship with craters, and their morphological characteristics. To address these issues this thesis is divided into the following sections. Section 2 discusses the survey setup and methods used in the search for EFFDs. Section 3 examines the physical properties of EFFDs including structures, textures, and morphology. This is done by the use of high resolution imagery and focuses on developing an archetypal description of the features as well as classifying systematic variations in morphology. Section 4 looks at the regional context in which EFFDs are found and examines EFFDs' relationship with nearby regional features, the role of erosional and depositional processes, and their latitudinal and global distribution. Section 5 focuses on the relationships between the EFFDs and the craters on which they are situated with particular attention to the orientation of EFFDs relative to their location on the crater. Finally, in section 6 I will discuss my conclusions and propose that EFFDs are sublimation pits located on crater rims due to the local elevationally-controlled erosion rates exposing volatile rich material. 


\section{SURVEY METHODOLOGY}

\subsection{Introduction}

EFFDs were first identified during an investigation of the Southern Highlands where it was noted that a significant number of craters possessed conspicuous depressions located near the rim. The features were of interest as they appeared to be restricted solely to areas in the mid latitudes with no obvious fluvial, aeolian, or tectonic cause. A study was designed to further investigate these features at multiple spatial scales to understand their morphological properties, local setting within the landscape, and global distribution. A series of four surveys consisting of a preliminary search, a latitudinal search, a systematic survey of a study area, and a high resolution image search were conducted to examine the morphology, relationship to hosting craters, and global distribution (Figure 1).

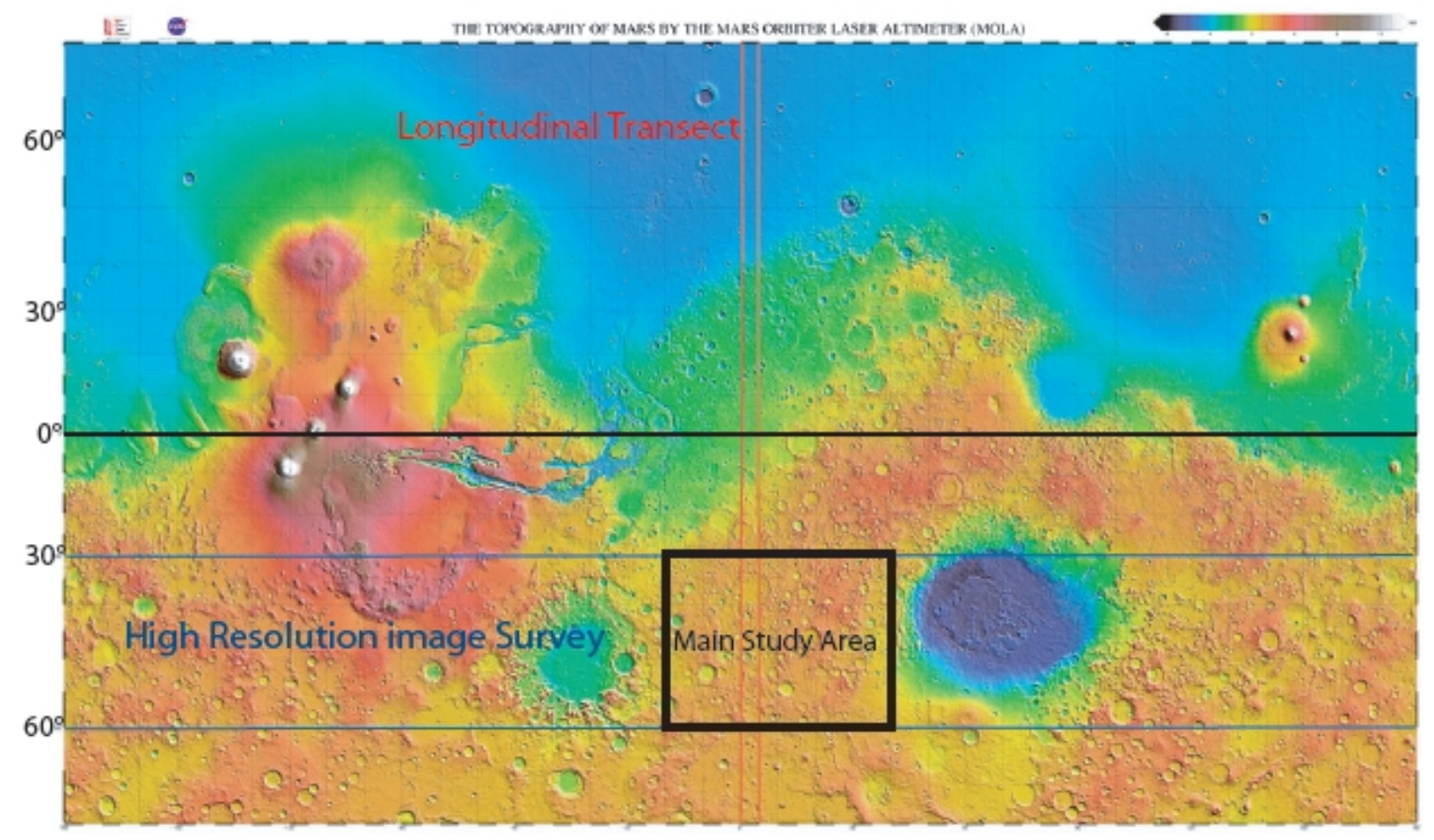

Figure 1: Study area locations 


\subsection{EFFD Definition}

The rough and irregular surface of the Martian Southern Highlands has many depressions and irregularities which dot the landscape. As such, a detailed description of characteristics which define an Elevated Flat Floor Depression (EFFD) is necessary to conduct a systematic evaluation. Based upon the preliminary search, I defined EFFDs by the following diagnostic characteristics.

1) EFFDs are depressions completely enclosed by a steep, well defined boundary scarp. A number of similar looking features have were identified on mid latitudes craters walls producing only one scarp face. These features may be related to EFFDs but for the purpose of this study were not included.

2) The edges of the scarp must be relatively smooth and continuous with abrupt transition from the rim to the floor. Depressions with fracture patterns, fault-like troughs and rounded edges are likely related to different formative processes and were not considered. Only features which exemplify these unique characteristics were considered EFFDs and included in this study.

\subsection{Global Distribution}

Multiple regions on Mars were examined to assess areas of possible concentrations. Our preliminary search indicated that EFFDs seemed to be concentrated in the latitude band around $45^{\circ} \mathrm{S}$. Their distribution across the south appeared to be fairly consistent on the cratered highlands with noticeable gaps in the Tharsis, Hellas and Argyre regions. EFFDs were identified in the northern hemisphere but were less frequent. 


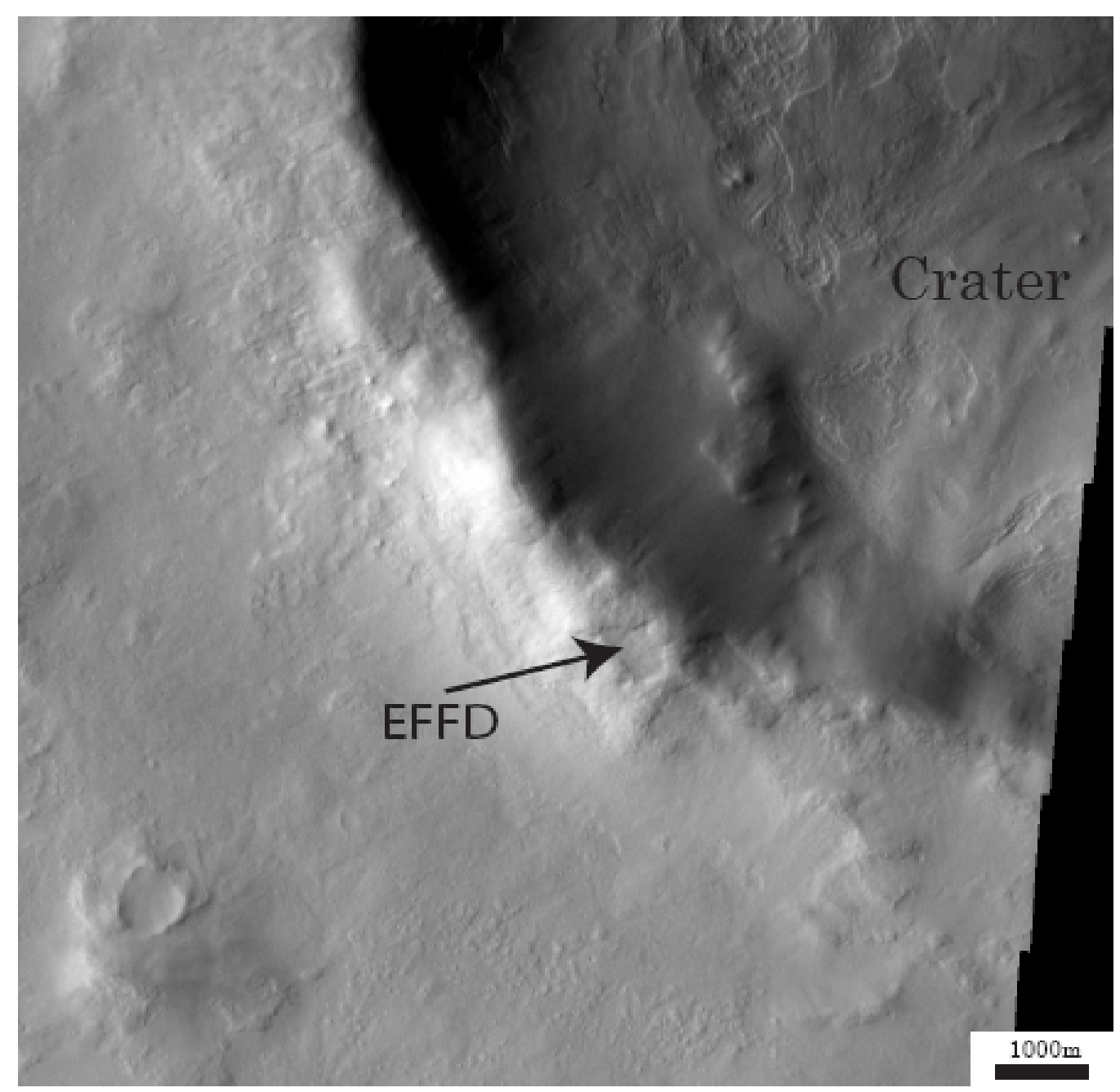

Figure 2: Elevated Flat Floor Depression(EFFD) located on a crater rim. THEMIS VIS V20343002

\subsection{Surveys}

\subsubsection{Preliminary Survey}

A preliminary search of $\sim 1,500$ images was begun in the southern hemisphere to locate representative EFFDs and assess the feasibility of a full project. This survey had multiple goals of determining suitable image types, formalizing a set of diagnostic characteristics of EFFD and creating a search methodology, defining regional variations and distribution, and locating a study site for a detailed examination. 
Many imaging systems have been in orbit around Mars and have produced multiple data sets with a wide range of resolutions and coverage. For the preliminary search I attempted to identify which image types were capable of resolving EFFDs. The image types evaluated and a brief description are as follows.

Viking: Viking images are some of the earliest mid level imagery from the 1970's and covers most of Mars at a resolution of around $400 \mathrm{~m} /$ pixel.

THEMIS: Thermal Emission Imaging System is currently operating over Mars on the Mars Odyssey Orbiter since Oct. 2001. THEMIS produces two image sets, a Visible Imaging Subsystem (VIS) which has an $18 \mathrm{~m} /$ pixel resolution and an Infrared system (IR) with a $100 \mathrm{~m} /$ pixel resolution and covers approximately $20-30 \%$ of the surface.

MOC: Mars Orbital Camera was on the Mars Global Surveyor which orbited Mars between 1997 and 2006. MOC has a resolution between $2-6 \mathrm{~m} / \mathrm{pixel}$ and has limited coverage across the planet.

CTX: Context Imager is aboard the Mars Reconnaissance Orbiter which has been orbiting Mars since 2006. It was designed as a context camera for the HIRISE system and has a resolution of $6 \mathrm{~m} / \mathrm{pixel}$ and has limited coverage of the planet.

HRSC: High Resolution Stereo Camera is a system on the Mars Orbiter Express and takes images of up to $2 \mathrm{~m} /$ pixel. HRSC is also unique as it is designed to take stereographic images of the surface with highly variable resolution and lighting conditions.

HIRISE: High Resolution Imaging Science Experiment is aboard the Mars Reconnaissance Orbiter which has been in orbit around Mars since 2006. HIRISE has the highest resolution camera to date with images of up to $0.3 \mathrm{~m} /$ pixel, however, only a fraction of the planet's surface is covered. 
Images of all types were examined in areas of known EFFD concentrations to determine usability based on resolution, coverage, and ease of use. It was concluded that Viking and THEMIS IR resolutions were too coarse to identify EFFD scale objects and were not included in future searches. THEMIS VIS images and MOC images were found to be the most effective in locating EFFDs due to the large image area, significant number of images to produce a global coverage, and manageable file size for quick browsing. These two image types did not, however, have enough resolution to distinguish morphometric characteristics of EFFDs. CTX, HRSC, and HIRISE images were able to resolve variations in EFFDs but detecting EFFDs was much more difficult as there were fewer total images and large file size made browsing difficult. For this project the bulk of the images examined were THEMIS VIS and MOC images and the properties investigated were chosen to be identifiable at those scales. The higher resolution CTX, HRSC and HIRISE images would be used for most of the morphometric descriptions of EFFDs in used in chapter 5 and THEMIS and MOC images were used to examine crater relationships and regional distributions in sections 4 and 5.

\subsubsection{Focused Study Area}

Based on the preliminary and latitudinal surveys a focused study area was established in the Noachis Terrace region between $340^{\circ} \mathrm{E}-40^{\circ} \mathrm{E}$ and $30^{\circ} \mathrm{S}-60^{\circ} \mathrm{S}$ that contains approximately 4000 THEMIS and $2500 \mathrm{MOC}$ images. This location was chosen due to the homogeneity of the landscape and presence of known EFFDs. This study area was designed to study regional and crater specific relationships providing a data base of EFFDs under uniform conditions so that significant statistical trends could be observed.

The latitudinal boundaries were chosen at the perceived latitudinal boundaries of EFFDs

identified during the preliminary search. In this study area every VIS (18m/pixel), HRSC (10-20 
$\mathrm{m} /$ pixel), CTX (6 m/pixel) and MOC (2-6 m/pixel) and HIRISE was examined for EFFDs covering an estimated $50-60 \%$ of the study area.

\subsubsection{Latitudinal Survey}

At the beginning of the project it was noted that EFFDs appeared to be latitudinally constrained with both the equatorial and polar regions of Mars devoid of them. The latitudinal survey was designed to address the range, mean, and distribution of EFFDs across the whole planet. To accomplish this, a $5^{\circ}$ wide N-S transect was chosen between $0-5^{\circ} \mathrm{E}$ and every THEMIS VIS image in that corridor was examined. To ensure the impartiality of the observer, the THEMIS images were downloaded based on the date taken rather than location and evidence of EFFDs was noted without reference to the latitude. Though the latitudinal distribution likely varies slightly with longitude I believe that the observed distribution is representative of EFFD latitudinal distribution.

\subsubsection{High Resolution Image Survey}

A high resolution image search was conducted in an attempt to understand the fine details of EFFDs. Every available CTX, HRSC and HIRISE image between the $35-60^{\circ} \mathrm{S}$ across the entire planet was examined. These cameras have a resolution in which fine scale features can be observed. Particular attention was paid to the walls of the depression looking for preferential orientation of morphologic features as well as general characteristics. In this survey I examined 750 HiRISE, 2000 CTX, and 300 HRSC images. 


\section{EFFD MORPHOLOGY}

\subsection{Introduction}

The difficulty in conducting direct experiments on Mars has made the description and interpretation of landforms key to our understanding of Mars. By comparing Martian features to similar Earth analogs we can infer the processes that occurred on Mars. This section will describe EFFDs appearance in the high resolution imagery. In these images I was interested in EFFDs textures, slope breaks, morphologic properties, and diagnostic features. My examination suggest that EFFDs are similar to sublimation features on Earth suggesting that subsurface ice is a main factor in EFFD development.

\subsection{Background}

The morphology of landforms has long been used to infer the processes that have acted on a landscape throughout its history. Mars and Earth both have many diverse features and terrains but EFFDs' morphology is distinct due to the steep depression wall transitions in an otherwise smooth terrain. Features with similar morphologies have been found on Mars such as alases (Figure 3a), sublimation pits on the edges of pedestal craters (Figure 3b), grabens (Figure 3c), pits on outflow channels, thermokarst in outwash plains, beheaded pits on debris-covered glaciers and the "Swiss Cheese" depressions (Figure 3d) near the southern polar region [Kadish et. al. 2008, Marchant 2007, Bryne 2003]. Most of these features are periglacial in origin and are thought to form from sublimation of subsurface volatile rich material.

Of particular interest to my project due to their similar morphology are scalloped depressions (Figure 3e). These pits are a few meters deep and have a scooped appearance with asymmetric slopes. Scalloped depressions are thought to be initiated by dust devils traveling 
over a volatile rich but armored surface and then grow by solar radiation driving off the volatile content of the soil creating a top down erosion which enlarges the depressions [Zanetti et. al. 2008, Morgenstern et. al. 2007]. I believe that scalloped depressions are similar to EFFDs differing only in the triggering erosional process which removes the armored surface and the dependence on solar induced sublimation.
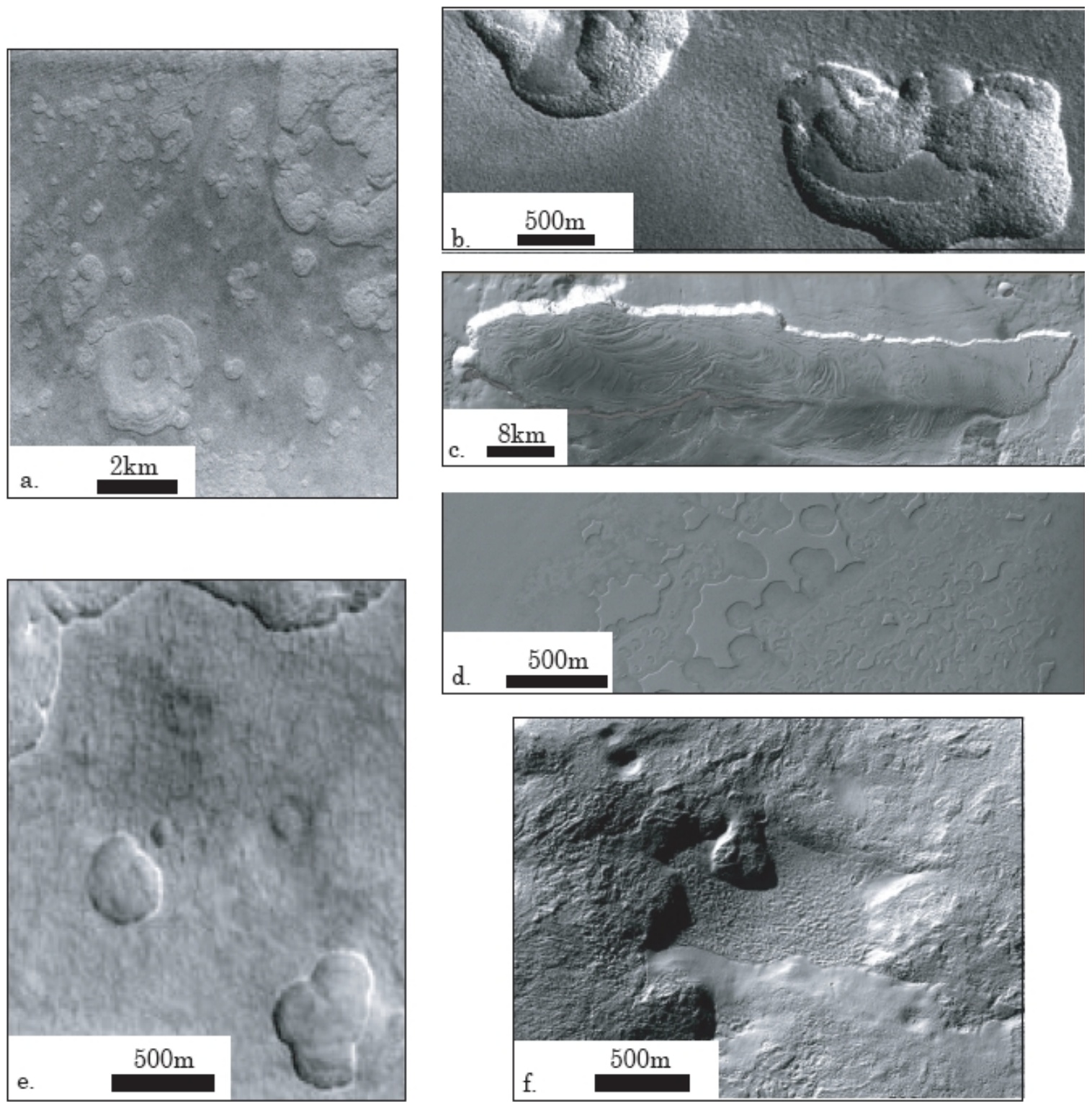

Figure 3: Types of enclosed depressions on Mars. (a.) Alas field (Viking image 466B96). (b.) Pedestal crater troughs (CTX image P01_001555_2430). (c.) Graben features on a crater slope (HiRISE image H1034). (d.)"Swiss Cheese" terrain in the polar region (MOC image M034994). (e.) Scalloped depressions (MOC image E503354). (f.) EFFD on a crater rim (MOC image S2200246). 


\subsection{Observed Characteristics}

Though the diagnostic morphology used to identify EFFDs remains fairly constant, a number of characteristics of EFFDs vary from location to location. I have categorized these differences and investigated their relationship to each other as well as their spatial distributions. The following section outlines the fine scale characteristics of EFFDs, the morphometric measurements, and the significant observed correlations. Many correlations were examined, a list of which can be found in a I, but in this section only significant correlations are described.

Size and Orientation:

Most EFFDs are elliptical in shape. The major and minor axis length as well as the orientation of EFFDs were measured in Photoshop and converted to distances using the $18 \mathrm{~m} /$ pixel for the THEMIS images and the photo-specific scaling for the MOC, CTX, HRSC and HIRISE images. The major axis was measured along the center of the depression and the minor axis was measured perpendicular to the major axis in the location of greatest width. At the same time measurements of the major axis of EFFD orientation relative to north were taken to the nearest degree.

Clustering:

Clustering refers to the presence of multiple EFFDs on a crater rim. We designate EFFDs as clustered when multiple EFFDs occur near each other and isolated if there are only one or two features on a crater rim. In some locations clustering was so great that EFFD-like features interconnected with each other through narrow troughs. To categorize this distribution we rated each EFFD on a scale ranging from 1 (isolated) to 5 (interconnected). Included in this measurement are any EFFD-like depressions on the crater rim (Figure 4). 


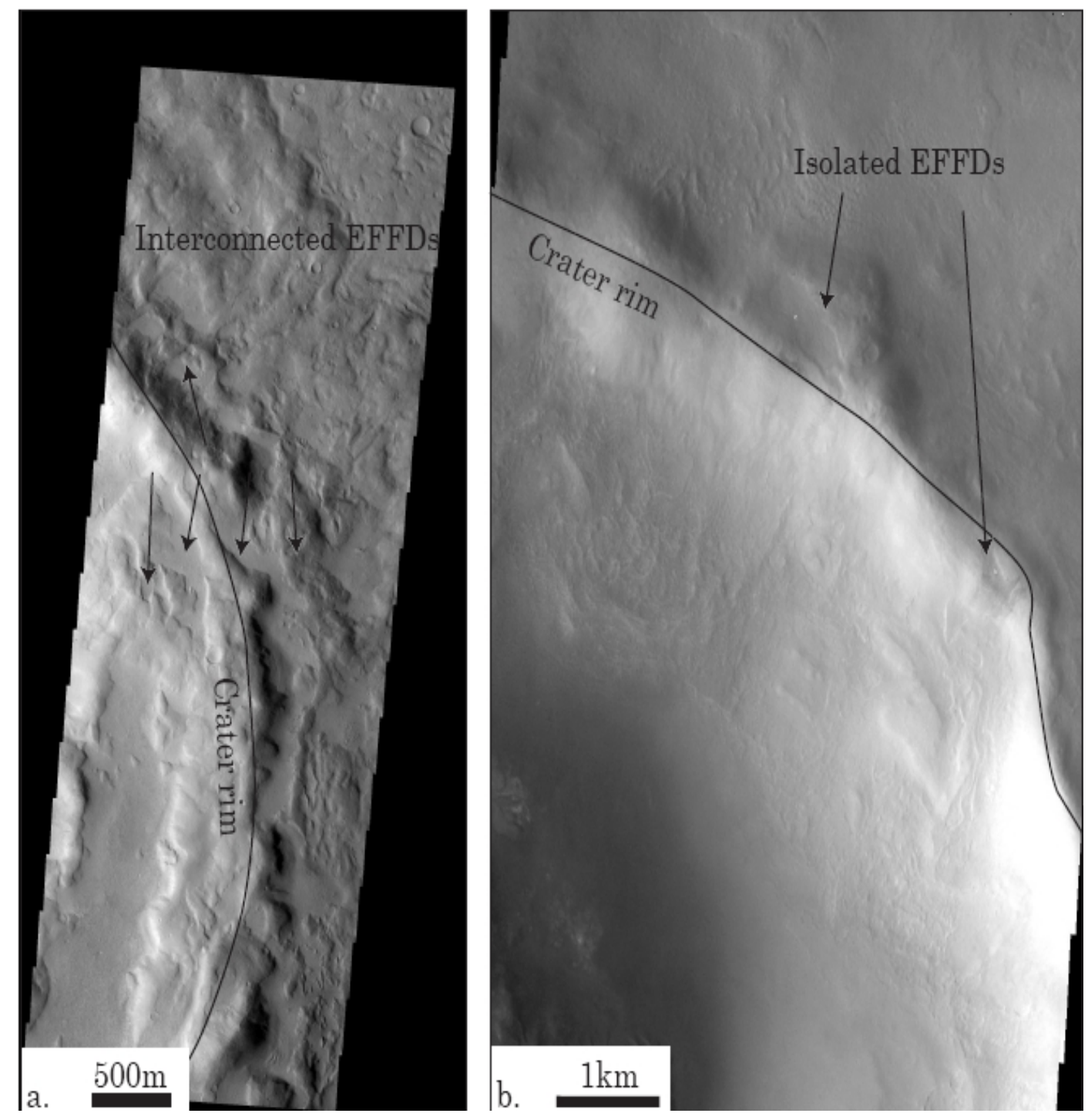

Figure 4: EFFD clustering types on crater rims. (a.) Interconnected Terrain (b.) Isolated EFFD

\section{Slope Asymmetry:}

To search for a regional or global influence, measurements were made of the width of the interior slope of EFFDs in four directions. As I was unable to develop a reliable method to measure EFFD depth due to lack of high-resolution stereo images, depths were estimated by assuming that EFFD scarps have similar slope angles near the angle of repose of $33^{\circ}$. These measurements were only made on the high resolution imagery as THEMIS and MOC image resolution were too coarse to use this method. 
Irregularity:

Irregularity refers to the degree to which the EFFD outline deviates from a perfect ellipsoid. This variability includes small irregulaties in sidewall planform as well as short troughs which extend from EFFDs. Measurements were taken in an attempt to partly quantify this variation and estimates were made on the irregularity of the edge on a qualitative scale of 1(elliptical) to 5 (highly irregular).

EFFD Texture Type:

The surface texture immediately in and around the EFFD was characterized by factors related to the age and amount of modification that was observed. The three texture types identified are as follows. Fresh: Little or no aeolian cover on the floor, steep scarp walls, and abrupt transitions between the two (Figure 5a). Muted scarp: describes a depression where some process, either depositional or erosional, has emplaced a mantle or colluvium over the scarp creating a slightly muted topographical relief (Figure 5b). And Extensive Mantle: this term is used to describe areas that have been extensively covered by a mantling unit which is thought to be a ice dust mixture that covers large parts of the landscape(Figure $5 c$ ). In addition, the presence of resolvable boulders and erosional backwasting of scarp facies was noted where present in high resolution images (Figure 6). 

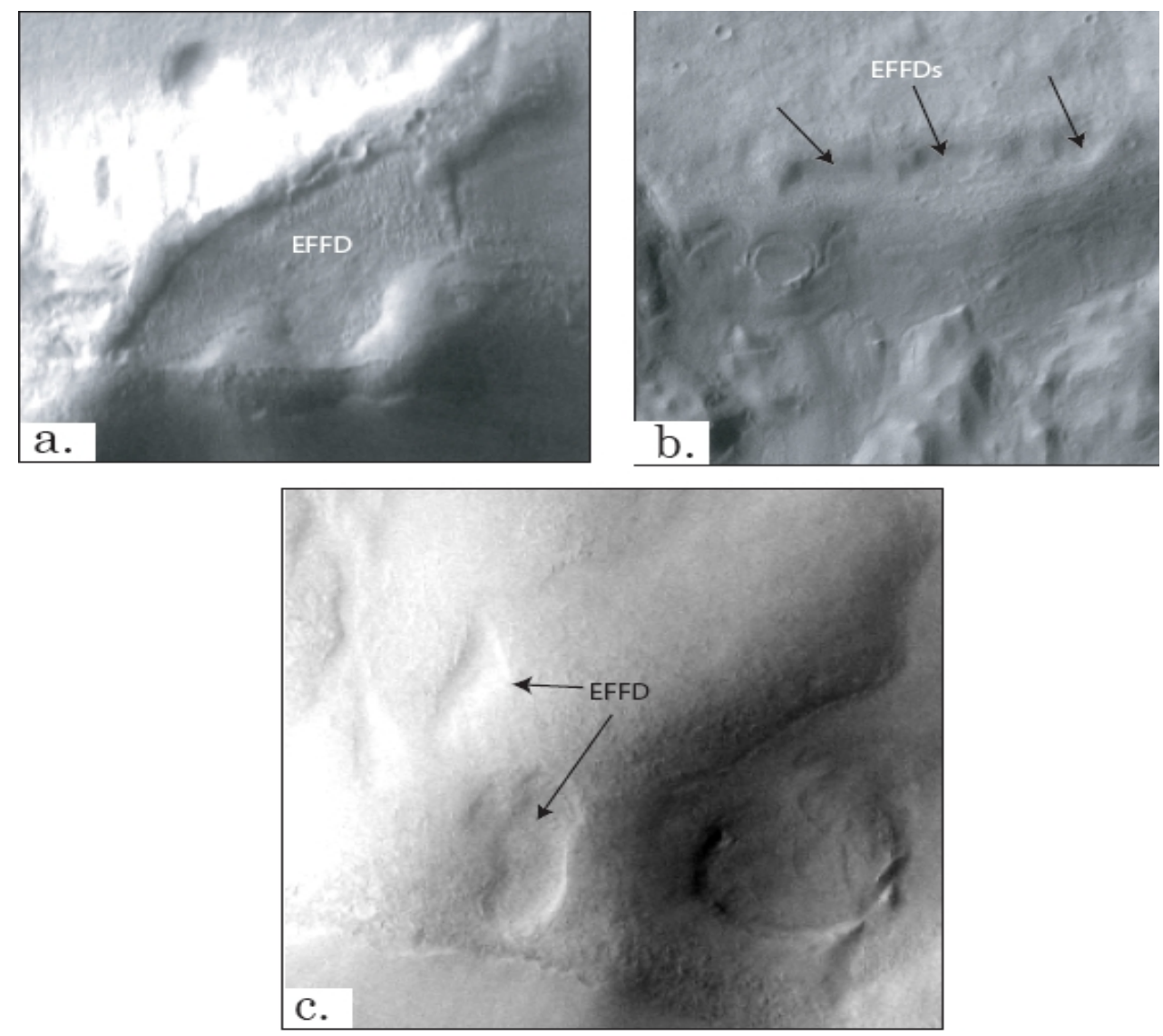

Figure 5: EFFD terrain types. (a.) Fresh EFFD. (b.) Muted EFFD. (c.) Mantled EFFD.

\subsection{Results}

\subsubsection{Shape Morphology}

The shape of EFFDs tend to be elliptical with the major axis of the EFFD ranging from 400 to $2000 \mathrm{~m}$ long with an average ellipticity of 0.818 or just under $2: 1$ length to width ratio with a range between $1: 1$ and 7:1. The planimetric shape is consistently oval with infrequent jutting scarps or ravines. Occasionally, in interconnected terrains the morphology will become slightly more irregular but still retain the basic smooth concave edges. 


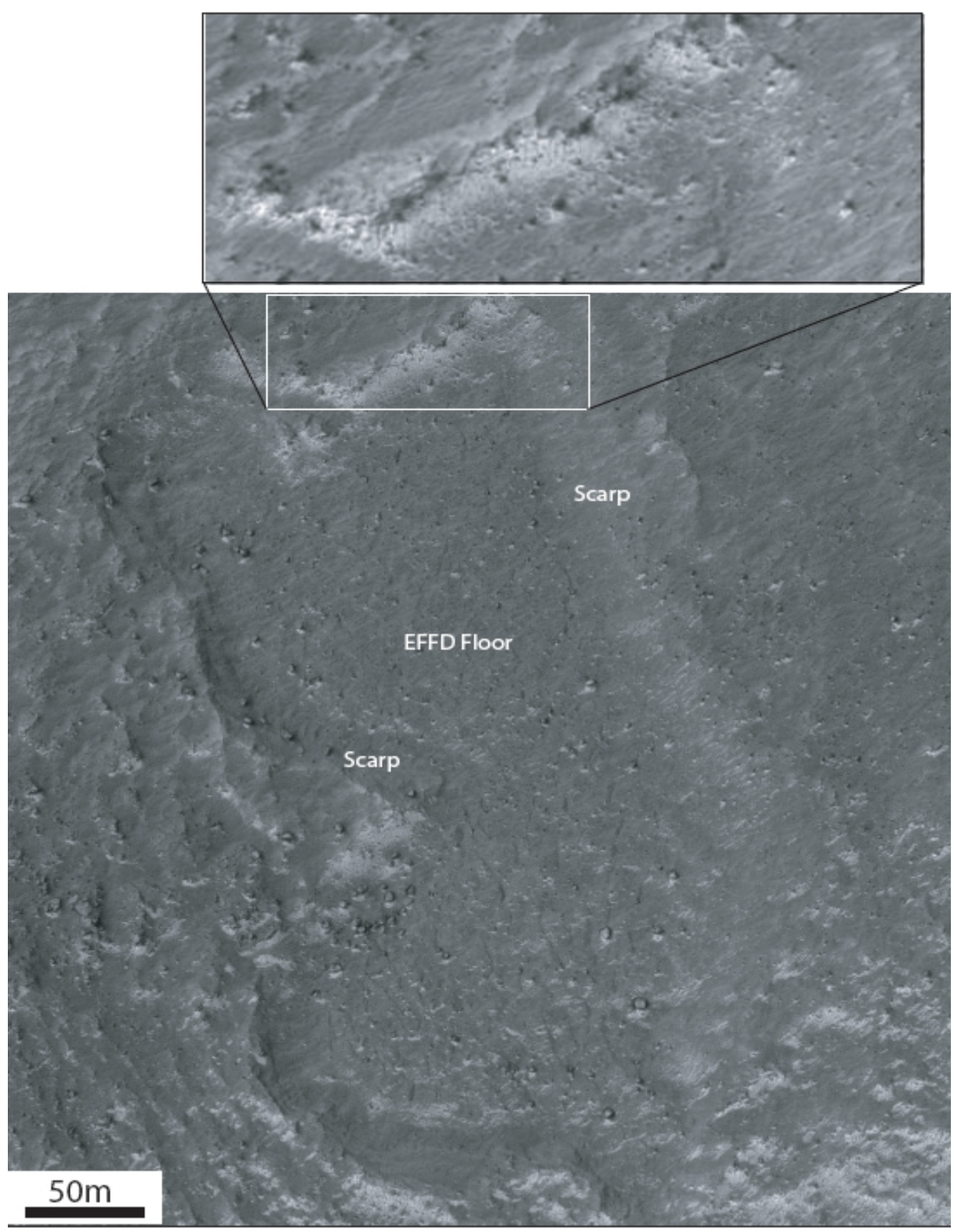

Figure 6: High resolution image of an EFFD with distinctively sharp scarps and flat floor which is completely enclosed. (HiRISE image PSP_002023_1275).

\subsubsection{Scarps}

Examination of the EFFDs in high resolution images show that the characteristically sharp scarps of represent approximately 20 meters $+/-10 m$ elevation difference from the floor to the rim. The rim's elevation follows the elevation of the surrounding landscape and does not feature a raised or transitional slope; rather it abruptly terminates into a steep scarp with visible 
cliff faces near some tops and large boulders littered near the base (Figure 6). Significant troughs extend from just under $20 \%$ of the EFFDs examined. These are rugged and narrow chasms that extend a few hundred meters from the EFFD before abruptly truncating and most slope towards the EFFD.

\subsubsection{Slopes}

The interior scarp walls of EFFDs appear to be composed of material derived from erosion of the EFFD sidewall and are likely loose and unconsolidated material rather than exposed bedrock. The slopes appear to be at or near the angle of repose based on visible appearance, the occasional cliff faces, and the presence of some boulders near the base. Generally, the slopes show a smooth texture but some locations within the EFFDs appear to have been more recently disturbed with areas of boulders, cliff forming facies, and crag-like rims.

\subsubsection{EFFD Floor}

The floors of EFFDs tend to be remarkably uniform in both texture and topography. The floors of the EFFDs are generally similar in texture to the surrounding landscape with a slight aeolian cover creating a hummocky texture. The floor material does not have the albedo of loose unconsolidated active aeolian dunes that are found in some locations of the planet; rather, it is light in color and has only subtle wind features. The orientations of the aeolian features are not always similar to the surrounding landscape and the surface is generally smoother and less rough in appearance in the surrounding area than in the EFFD. None of the photos exhibit any significant hills, aeolian deposits, or mesas on the EFFD floor. The floor tends to slope at the same angle as the surrounding landscape which, given the proximity to the apex of the crater, is typically only a couple of degrees. The floors of EFFDs also appear to be uniform in depth among nearby clustered EFFDs. 


\subsection{Discussion}

The morphological details of EFFDs suggest that they are a younger feature than the surrounding landscape. Close examination of EFFDs show sharp edges and angular transitions in an otherwise smooth and weathered terrain. This well defined appearance is especially interesting as small scale features are the first to be removed in a terrain that has experienced multiple erosive and depositional events. The textures of the slopes also indicate that EFFDs are superimposed on the landscape. The degradational appearance and presence of boulders near the base of the slope suggest that some backwasting has acted on the scarp face, though given the sharp slope break between the slope and floor, it is unlikely that EFFDs were primarily formed by gravity driven backwasting and slumping filling in a depression and enlarging its edges. In such a scenario we would expect to see a gradual transition to a shallower slope angle near the floor and extensive boulders near the floor as a result of accumulation of mass wasting. Instead, I believe that large scale slumping is limited to areas of steep cliff faces and is not responsible for significantly increasing the size of EFFDs. If extensive gravity driven scarp retreat did occur, one would expect a much more subdued scarp transition.

The floors of the depression are masked by an aeolian cover of unknown thickness and are similar in appearance to the surrounding landscapes. Due to this similarity I believe that the material is likely similar but is likely only a thin veneer covering the base. The floors of the depressions have a slight hummocky appearance with no visible build up of material on either side of the floor suggesting little loose material available for transport on the floor. The total amount of saltation transportation of material seems to be fairly limited and the depressions do not appear to be sediment sinks. The one oddity with the winds influence on EFFDs is the slight but visible change in direction of the yardangs and wind streaks within EFFDs compared to the surrounding area which I attribute to local topographical control of the local winds. 

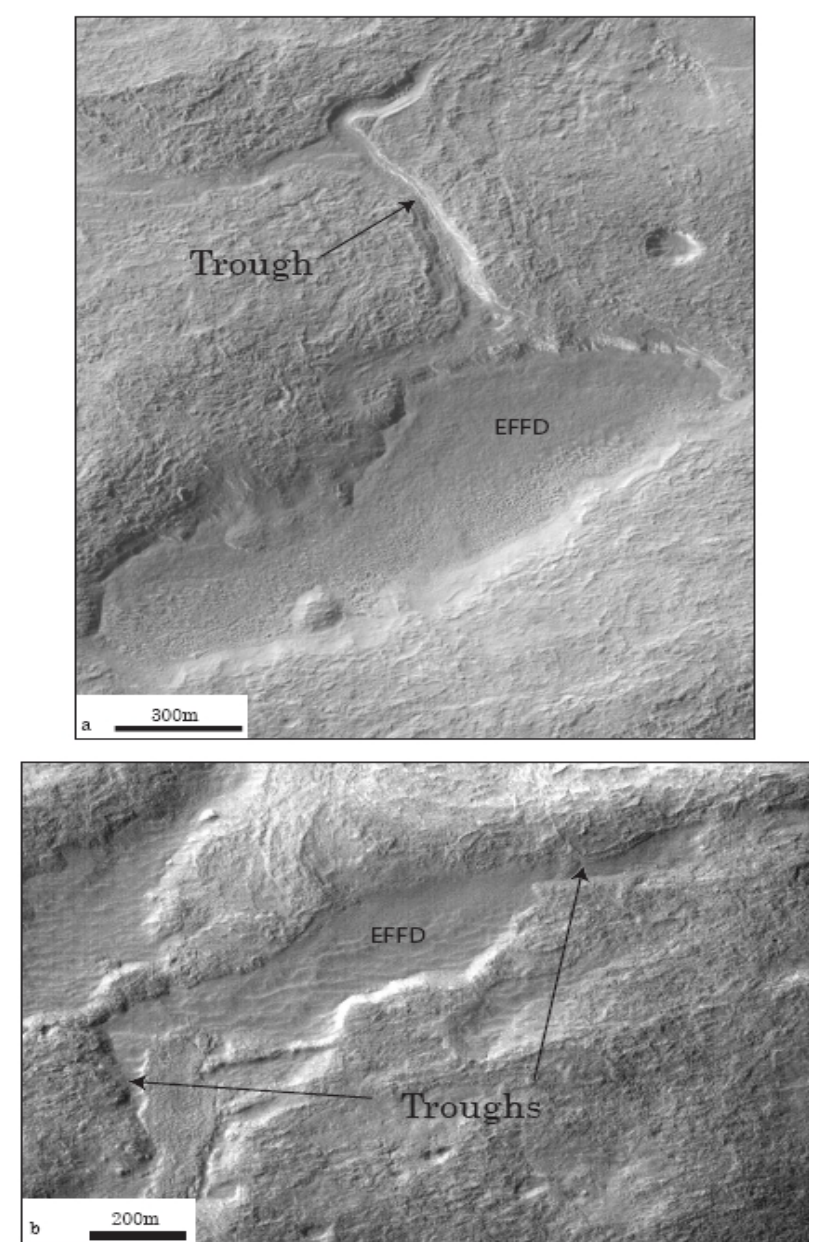

Figure 7: Short troughs that extend from some of the EFFD depressions. (a.) CTX P010015581325 (b.) CTX P030022711367.

The trough-like depressions that extend from EFFDs do not appear to be fluvial in nature as they are deep, rugged, and short with too small of a drainage area to gather sufficient precipitation to make deep incisions. Some features do contain flow lines which I interpret to be localized ice related creep. EFFDs' mountain top location, small size, and lack of inwardly sloping local topography make it unlikely to be a local basin where water would collect and overflow (Figure 7a \& 7b).

In fact, EFFDs do not seem to influence the surrounding landscape nor do EFFDs seem to concentrate in any morphologically distinct region other than near the top of crater rims. There is no evidence of increased erosion or deposition in the nearby landscape and EFFD scarps abruptly begin in the landscape. Outside of the interior of the EFFDs the landscape shows no 
modification or evidence of disturbance related to EFFD presence suggesting that regional processes alone can cause that amount of incision.

The uniform depth and flat floors with little visible infilling suggests a of structural controlling the depth of EFFD which I believe is related to the mantle unit. A purely erosional feature into a uniform material should have variable depths and sizes as local factors would influence the erosion rate and depth that incision is possible. This would help explain why the floors have the same slant as the landscape in which they are situated as any stratigraphic layering would also follow the slope of the crater as once they breach through the mantle layer sublimation would cease.

If we assume that EFFDs are a late stage modification of the landscape then the key question is how do you account for the observed volume loss? As noted above, gravity and liquid water do not seem to play a key role as EFFDs lack a pathway for overland sediment transport such as a valley or steep slope limits. Wind, though it has slightly modified the EFFDs, does not appear to be extensive enough to solely create EFFDs. The isolated nature of many EFFDs, the lack of significant wind related features, the uniform depth, size, and symmetry of the EFFD floors suggest another processes involved which I believe is aeolian.

Subsidence features found on Earth seem to have the most morphological similarity to EFFDs. Alases, karst, thermokarst, and even structural subsidence all display this typical steep sided and flat floor appearance and addresses the question of observed volume loss (Figure 10). The morphology, however, does not contain any clues as to the type of subsidence and there are many processes which can cause material to be removed. However given the latitudinal dependence and the similarity in location and appearance to other ice related features on Mars I believe that ice sublimation is the most likely process. 


\section{REGIONAL LANDSCAPE AND GLOBAL DISTRIBUTION}

\subsection{Introduction}

The landscape of Mars is highly variable in age, composition and morphology. Knowing the local and global context as well as identifying related features places EFFDs in a setting which helps constrain the possible environmental conditions in which they could form. In this section I examine the regional context of EFFDs by observing other proximal features within a few hundred $\mathrm{km}$ from EFFDs as well as the global distribution of EFFDs. The surrounding features and global distribution of EFFDs suggest that ice and periglacial processes play an important role in EFFD development.

\subsection{Background}

\subsubsection{Current Conditions in the Mid-Latitudes}

My main study site is located in the Southern Highlands of Mars in the region of Noachis Terra. Current conditions are quite cold and dry with only a limited number of processes acting on the planet's surface. Aeolian activity is the current dominant process on the landscape and is the main transporter of material across the planet. Erosion rates are a fraction of their terrestrial counterparts at around $0.0004 \mathrm{~mm} /$ year [Golombek 1999]. Tectonic modification of the surface is limited and volcanism is centered almost exclusively in the Tharsis region. The end result is that morphologic features on Mars can be quite persistent and landscape modification occurs only over the geologic timescale.

The highlands consist of ancient, rough, mafic to ultramafic rocks that have been highly modified by impact events creating a megabreccia regolith $1 \mathrm{~km}$ in depth with extensive fracturing and limited lava resurfacing in some locations [Hartmann and Neukum 2001]. This 
base unit is covered by a fine-grained, non-consolidated, weathered material in a homogeneous and presumably thin, blanket that is interspersed with larger rock fragments ejected from crater impacts.

Much of the landscape has had recent (late Amazonian) modification by numerous icerelated processes such as flow of mountain-flank glaciers, fan-shaped and lobate deposits, parallel, converging and chevron-like lineations in potentially ice-rich deposits, lineated valley fill thermokarst lakes, patterned ground, slope asymmetry, debris mantles, lobate debris aprons, and rock glaciers [Soare and Roehm 08, Mahaney et. al. 2007, Shean et. al. 2007, Forget et. al. 2006, Head et. al. 2006, Page and Murray 2006, Head et. al. 2005, Levrard et. al. 2004, Li et. al. 2005, Costard and Baker 2001, Rossbacher and Judson 1981, Wade and De Wys 1968]. Recent work on small, young gullies on craters even suggests that some water source may still be active and capable of creating water related incision on steep interior crater rims[Heldmann et. al. 2007, Soare et. al. 2007, Mellon and Phillips 2001].

\subsubsection{Historical Conditions in the Mid-Latitudes}

The Martian highlands have not always been so arid and cold. Though there is a lack of consensus on a general climatic model of historical Mars, [Haberle et. al. 2003, Fanale 1992] many Noachian age (>3.5 Ga BP) locations show evidence of warmer and wetter surface conditions with extensive fluvial features [Goldspiel and Squyres 1991], alluvial fans [Moore and Howard 2005, Craddock and Howard 2002], extensively infilled craters [Forsberg-Taylor et. al. 2004, Craddock and Howard 2002], and deltaic deposits [Pondrelli et. al. 2008]. The extent and source for this water is still debated but evidence of multiple flow events and precipitation driven recharge are strong and indicate that precipitation occurred on a scale large enough to significantly alter the landscape [Cradock and Howard 2002]. 


\subsubsection{Planetary Climate and Hydrologic Cycle}

So where is this water now? Many researchers believe that a significant portion of the water is contained in the subsurface and recent measurements from the Gamma Ray Spectrometer indicate that ground ice and ice rich soils are present poleward of $40^{\circ}$ [Mellon et.

al. 2004, Boynton et. al. 2002, Mustard et. al. 2001]. Surface ice deposition also occurs seasonally with surface frosting documented at $24^{\circ}$ in the southern hemisphere [Schorghofer and Edgett 2006] and dynamic polar caps seasonal accumulating ice indicating a slow but present $\mathrm{H}_{2} \mathrm{O}$ cycle on Mars. The historical quantity and transport of water is much more controversial with stability ranges for surficial water and ice varying greatly due to multiple historic climatic shifts. Global climate variation on Mars occurs from ash and gas inputs into the atmosphere from volcanism and meteor impacts [Craddock and Howard 2002], and planetary obliquity changes. Martian obliquity angles are known to have drastically shifted due to the planets proximity to Jupiter and are thought to have ranged from $0^{\circ}$ to possibly $60^{\circ}$ [Laskar et. al. 2004]. Periglacial features are typically thought to be associated with periods of high obliquity [Chamberlain 2007, Head et. al. 2006, Levrard et. al. 2004]. Obliquity extremes of this magnitude shift the stability ranges of water and $\mathrm{CO} 2$ creating extreme seasonal, as well as millennial, obliquity driven climatic cycles which result in the large scale cycling of water across the Martian landscape [Haberle et. al. 2003, Mischna et. al. 2003]. Obliquity-driven climatic change has been suggested as the main driver for many ice and water surficial features across the planet [Chamberlain 2007, Head et. al. 2006, Levrard et. al. 2004] and extends both the duration and the range of ice and periglacial features into the mid-latitudes which are currently unstable for water or ice[Mustard et. al. 2001]. 


\subsubsection{Terrain Mantling}

Of particular interest in this landscape is terrain mantling which has occurred across much of the mid latitudes. Terrain mantling or softening is a term used to refer to a depositional layer of ice cemented dust of locally uniform thickness which has been deposited over many parts of the landscape resulting in smoothed and muted features. This mantling terrain covers large portions of the mid latitudes of both hemispheres between $30^{\circ}$ and $70^{\circ} \mathrm{N}$ and $25^{\circ}$ to $60^{\circ} \mathrm{S}$ and is distinct from mantle units in the equatorial regions in its ubiquitous distribution across the landscape rather than being concentrated in areas of low elevation. In places this mantle unit has been partially dissected or disaggregated resulting in a pitted or hummocky terrain. This feature has been attributed to repeated late Amazonian obliquity driven airfall deposition of ice and dust mixtures a few meters thick [Head et. al. 2003, Mustard et. al. 2001, Kreslavsky 2000].

\subsection{Observed Characteristics}

To assess the importance and relationship of EFFDs with the surrounding terrain, I examined a number of features in the landscape known to be related to aeolian, fluvial, or periglacial weathering. A correlation of any of these features would suggest that they may be related processes and that the forces responsible for EFFDs may extend beyond the crater rim where EFFDs are located.

\section{Latitude and longitude:}

The latitude and longitudinal coordinates of images containing the identified features were recorded from the primary image and subsequently marked on a THEMIS image mosaic for further interpretation and investigation of spatial distributions. 
Elevation:

Using MOLA data the elevation of EFFDs were recorded. Due to the difficulty in locating EFFDs in MOLA data, measurements were made to the nearest $50 \mathrm{~m}$.

Infill:

Crater infilling refers to the erosional modification and infilling a crater has undergone. This effect has been identified in many craters on Mars and is thought to be due to a variety of processes, particularly fluvial erosion and deposition and aeolian deposition [Frosberg-Taylor et. al. 2004]. I categorized crater morphology into three categories: 1) Ghost craters: The crater is completely infilled and can only be identified by a low remnant rim or a circular color pattern; 2) Highly infilled craters: Such craters have small rounded rims and extensive flat level floors; and 3) No significant infilling: The crater is either fresh (unweathered and young) or has only slight infilling. The purpose of this measurement was to identify correlations of EFFD occurrence to the regional erosion and thus the age and intensity of regional modifications by erosional and depositional processes. Measurements were made from a mosaic of THEMIS images covering approximately $20 \times 20$ degree quads within $100 \mathrm{~km}$ of the EFFD.

Valley Networks:

With EFFDs located on crater rims there is no direct interaction of valley networks and EFFDs; however, the nearby presence of fluvial features indicates the location once had surficial water from ground water or atmospheric sources. A strong correlation would be highly suggestive that water played an important role in EFFD formation. Fluvial activity was measured on a three-step scale. 1) Proximal: Valley networks occur within approximately $100 \mathrm{~km}$ of the base of the crater. 2) Nearby: Valley networks are within approximately $500 \mathrm{~km}$ of the crater. 3) 
Not present: No valley networks were found nearby. Measurements were made from a mosaic of THEMIS images covering 20x20 degree quads.

Gullies:

Gullies represent an important and controversial erosional feature found on some steep crater walls in the mid latitudes. Most interpretations suggest gullies are formed by water discharge from sources high on crater rims, either from melting of ice accumulations or from groundwater discharge [Heldmann et. al. 2007]. Their freshness and paucity of superimposed craters suggests that they may have been formed during the last high obliquity cycle [Soare et. al. 2007, Costard et. al. 2002] and there is even evidence that some of these features may be currently active [Schon and Fassett 2008]. Correlations with gullies would suggest not only a young time constraint but also indicate that either water or ground ice played a role in EFFD formation. Gullies were identified in both the original image as well as the THEMIS quad mosaics. Gullies were noted as either being present in the crater, present in adjacent craters, or not present.

General Landscape Morphology:

A "landscape morphology" category was created to address the overall erosional or depositional modification of the surrounding area and represents a suite of features rather than an individual landform. Landscape types were divided into 4 categories based on the relative extent of deposition or erosion observed. 

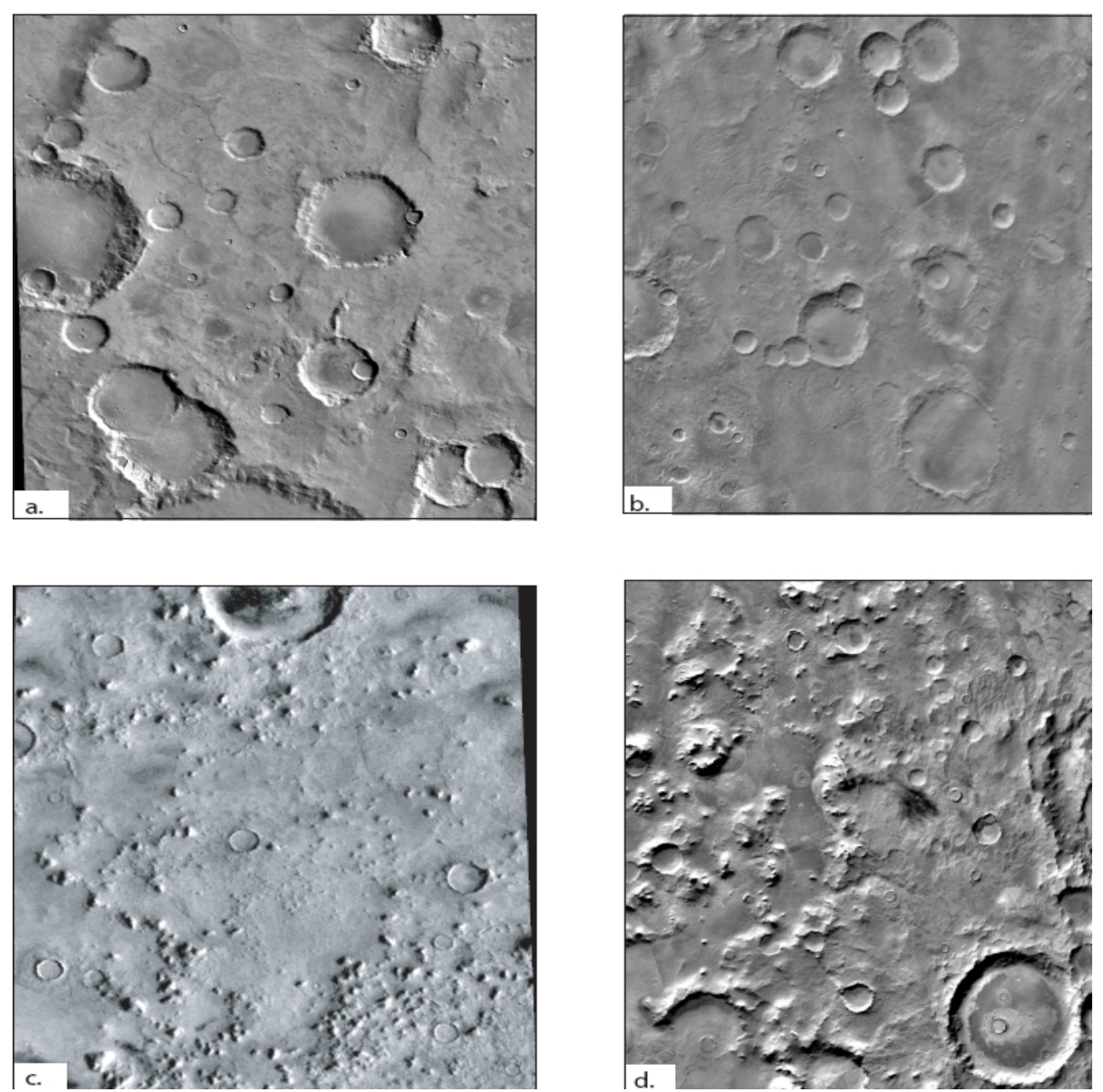

Figure 8. Landscape Types. (a.) Lightly mantled terrain. (b.) Heavily mantled terrain. (c.) degraded terrain. (d.) significantly eroded terrain.

The first type identified is a moderate mantling. Such a landscape is characterized by a light muting and smoothing of the surface and a lack of sharply-defined features but most underlying features such as details of crater rims are still visible. This is most likely the result of a relatively thin mantle layer being deposited over the surface or at least a slight aeolian cover. (Figure 8a)

The second type of landscape identified is a highly mantled landscape. These landscapes are characterized by an extensive covering over the surface and the muting of features to the point which many small scale irregularities have been removed and crater rims become rounded in appearance. (Figure 8b) 
The third type of landscape is degraded landscape. We characterized this terrain as having an irregular surface texture (particularly pitting) with evidence for recent erosional activity. (Figure 8c)

The fourth type of landscape is significant erosion. These are characterized by terrains with significant elevational changes or ruggedness likely caused by fluvial erosion and represent terrains that are significantly older and likely Noachian in age. Though these may have a light mantle over them in places it is difficult or impossible to tell due to the strong topographical relief (Figure 8d).

Periglacial evidence:

The surrounding area was examined for possible periglacial features which are common throughout the mid latitudes of Mars [Soare and Roehm 08, Mahaney et. al. 2007, Forget et. al. 2006, Head et. al. 2006, Page and Murray 2006, Head et. al. 2005, Levrard et. al. 2004, Li et. al. 2005, Costard and Baker 2001, Rossbacher and Judson 1981, Wade and De Wys 1968]. Periglacial activity indicates that the local subsurface cryosphere was active implying both the presence of ice as well climatic conditions favorable for either deposition or sublimation of that ice. I characterized features suggestive of periglacial activity in the primary image as well as on the THEMIS mosaic image where possible.

The periglacial features identified were 1) Patterned ground: Represented by reticular networks of faint lines of different albedos with little or no topographic relief (Figure 9a) [Page 2007]. 2) Viscous flow features: On the side of craters there are smooth and continuous ridges located on some steep crater slopes where material appears to have moved by flow as opposed to landsliding and have been suggested to be related to ice creep or local glacial flow (Figure 9b) [Milliken 2003]. 

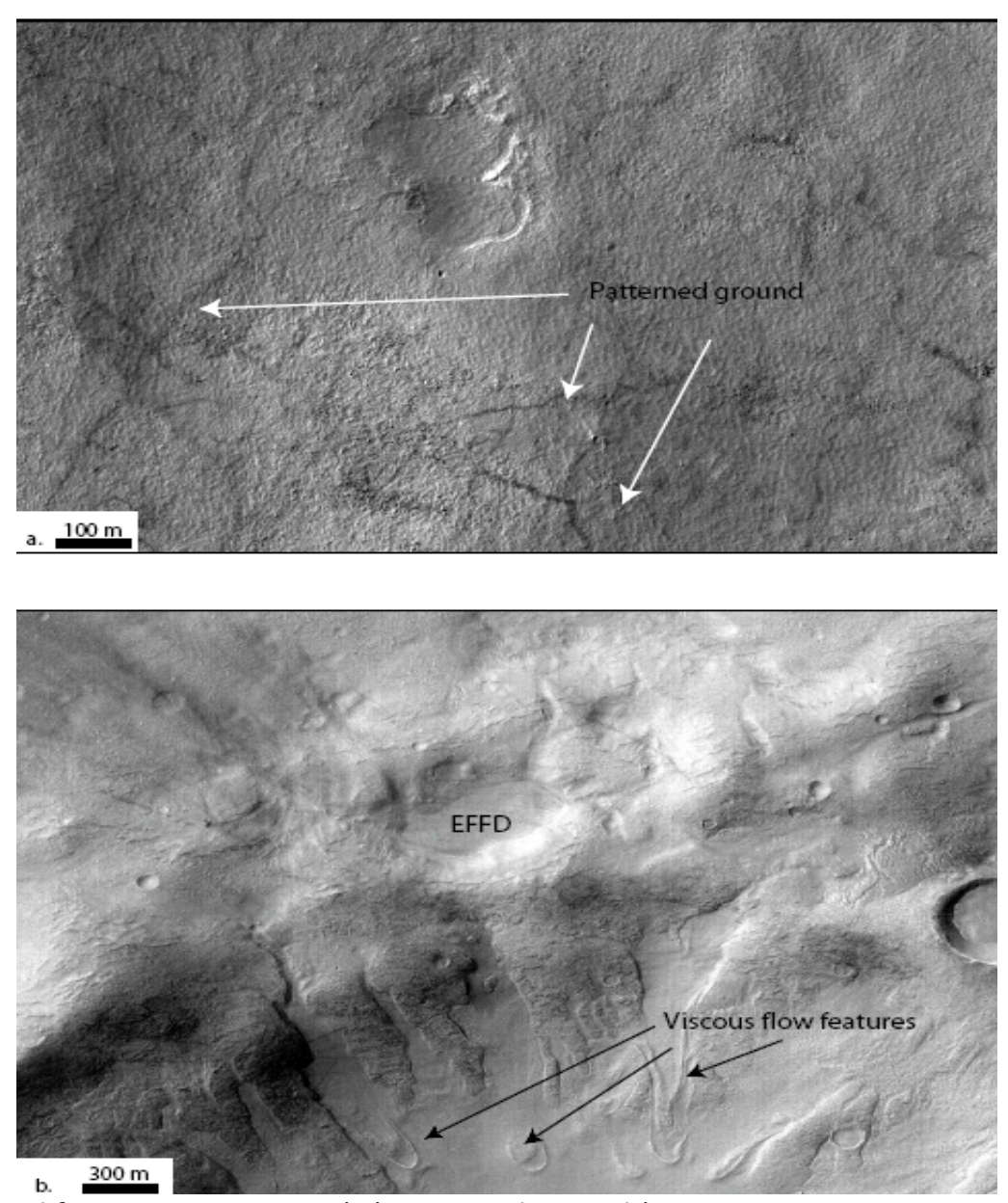

Figure 9: Periglacial features near EFFDs. (a.) Patterned ground (MOC image R1402789.

(b.) Viscous flow features CTX image P04_002456_1377

\subsection{Results}

\subsubsection{Global distribution}

Our examination of the latitudinal distribution of EFFDs indicates that they are centered around $42^{\circ}$ in the southern hemisphere and closely follow a Gaussian distribution around this mean with a standard deviation of 5.96 degrees and an $R^{2}$ value of 0.6589 to this curve (Figure 10). No EFFDs were found in the equatorial range between $0^{\circ}$ and $30^{\circ}$ nor were there any found beyond $65^{\circ} \mathrm{S}$. Latitudinal dependence was also found in the northern hemisphere in approximately the same range though the data set was much smaller and identifying a definitive range was not possible with the data collected. There did not appear to be any longitudinal 
variation of the distribution of EFFDs in our main study area of Noachis Terra. Our search across the mid-latitudes did identify some areas such as the Tharsis region, and the bottoms of Hellas and Argyre which have a low EFFD occurrence rate.

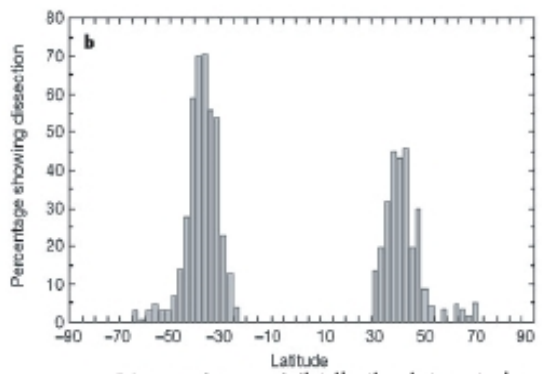

Dissected ground distribution intrpreted

to be ground ice.Mustard 2001
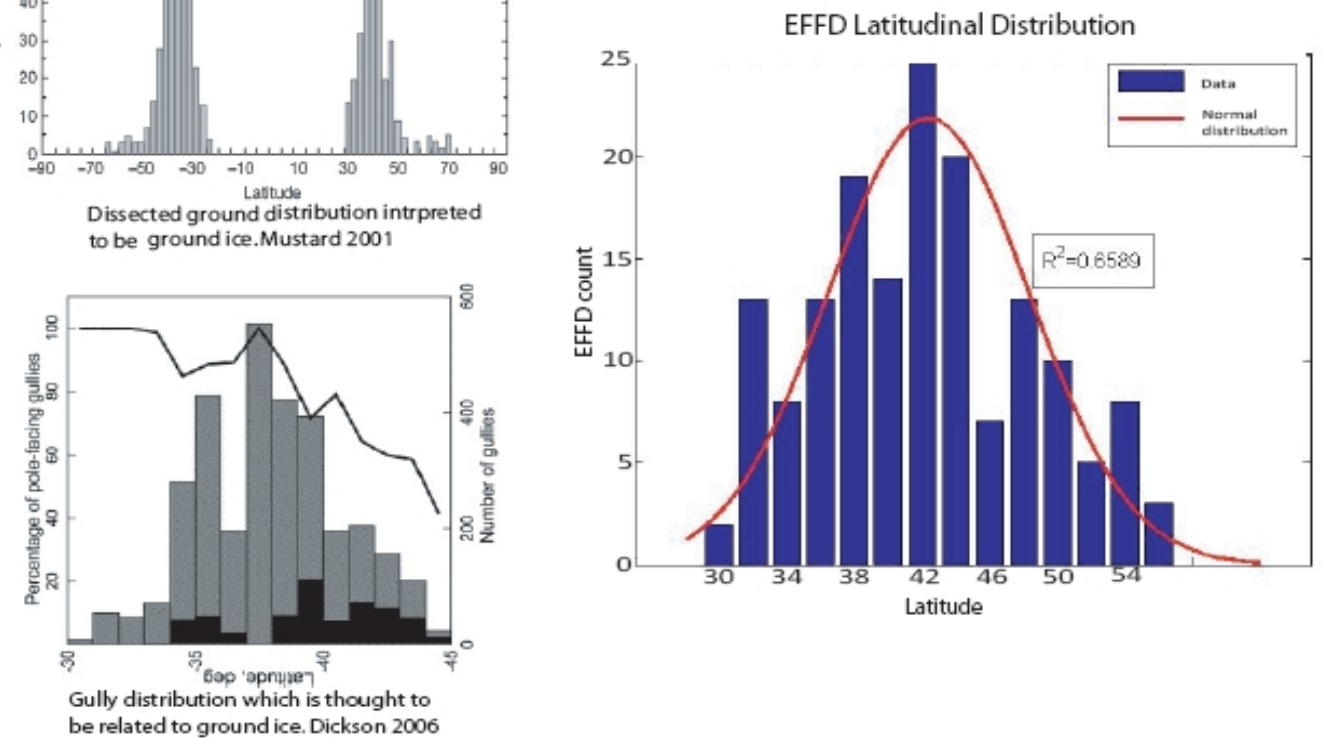

Figure 10: Latitude distribution of EFFDs relation to other Martian ground ice features.

\subsubsection{Elevations}

The overall elevation of EFFDs is distributed between $-4000 \mathrm{~m}$ to $3000 \mathrm{~m}$. Within the Southern Highlands, EFFDs are found at all elevations with no discernible preferences other than the natural distribution of elevations in the region. In addition, EFFDs have been found in the northern hemisphere which, due to the crustal dichotomy of Mars, is at a significantly lower elevation. 


\subsubsection{Proximal Landforms}

In examining the proximal landforms it was found that some form of mantling was associated with most EFFDs. Significant mantle deposits covered approximately $75 \%$ of the landscapes with only $5 \%$ being identified as having a heavy mantle. The mantling deposit's effect on EFFDs vary from none to slightly muted, especially in heavily mantled areas. Even in locations with muting, EFFDs appear to post-date the mantling deposits and are superimposed into it.

Presumed periglacial activity is present in $46 \%$ of the images in the form of pattern ground or ice flow features and is ubiquitous if one considers the mantle deposits are periglacial in origin. The most commonly observed periglacial feature identified is patterned ground which accounted for $32 \%$ of the periglacial features. The presence of periglacial landforms influenced the distribution of interconnected or well developed EFFDs with occurrence rates of interconnective terrains present in locations without periglacial features rising from $14 \%$ to $28 \%$ in the presence of these landforms.

Other landscape features had much lower rates of association with EFFDs than the periglacial features. The presence of highly degraded craters and eroded craters were $23.5 \%$ and $33.4 \%$ respectively. Such frequency of occurrence is typical for the entire Martian cratered highlands area given our large search radius. Similarly, the fluvial features and gullies relation is fairly low with fluvial features found near $20.6 \%$ of the features and $34.3 \%$ if we include the larger search area. Gullies were found in $14.7 \%$ of the craters with EFFDs and an additional $11.8 \%$ in the surrounding craters. 


\subsection{Discussion}

\subsubsection{Global distribution}

The latitudinal control on EFFDs is quite pronounced and is highly suggestive that ice plays a key role in EFFD development. This latitudinal band is similar to a number of other periglacial features identified in the area and the direct observation of proximal periglacial features suggests that EFFDs are related to ice processes. Though most EFFDs are located near ice related features no one type appears to be ubiquitous with EFFDs. This variety of proximal periglacial features and the unique morphological characteristics of EFFDs suggest that EFFDs are periglacial in origin but are formed by a separate processes.

The limited number of EFFDs found in the northern hemisphere, Tharsis and Hellas and Argyre regions, can likely be accounted for by the differences in morphology, elevation, and process suites acting in those areas. The northern hemisphere is much smoother than the southern highlands due to extensive volcanic resurfacing and does not possess the same abundance of craters and the extreme local elevation differences as occur in the southern highlands. Though only a cursory search of the area was made, the percentage of craters with EFFDs occurred at a similar rate to the southern highlands. The Tharsis volcanic region, although steep, contains few craters or local relief on which EFFDs could be situated where as the large impact basins of Hellas and Argyre have fewer craters in their base and have been covered with extensive deposits [Tanaka 2000] removing much of the high relief topography. EFFDs were observed on the upper rims of these basins well above the elevation where muting occurs. The absence of EFFDs in these locations indicates that the presence of crater rims and the elevational relief that they create is a necessary condition for EFFD development. 


\subsubsection{Mantling Unit}

The near ubiquitous presence of mantled terrains in locations with EFFDs suggests that a relationship exists between these two features. Though mantled units were not identified at all locations, the percentage is high enough, and thin mantle units difficult enough to identify, that I suspect that a thin mantle layer may also be present at the other locations. The shallow and relatively small scale of EFFDs suggests they are near-surface features and therefore would be highly influenced by a mantling unit. The mantle unit, as a mixture of dust and ice, appears to be the ideal substrate for depressions to form and numerous documented sublimation and thermokarst features have been associated with this deposit. [Mustard et. al. 2001, Morgenstern et. al. 2007].

Unlike many other periglacial features on Mars which are restricted entirely to the mid latitudes, the mantle unit increases in thickness and is more continuous as it approaches the poles and contains sublimation features well poleward of $60^{\circ}$. My observations of EFFDs show that they are restricted to a latitudinal band between $30^{\circ}$ and $60^{\circ}$ which places it equator-ward of most documented mantle-related sublimation features [Morgenstern et. al. 2007]. The reason for the northern boundary for many periglacial features is that poleward of $50^{\circ}$ ground ice becomes stable in the near subsurface [Mellon et. al. 2004] and the propensity for sublimation and hydrologic movement of ice and water decreases poleward. The similarity to scalloped depressions, a mantle related sublimation feature which are forced by solar radiation with a range further poleward, suggests that these two features are likely related but that EFFDs are forced by a process other than solar radiation. I believe that these circumstances help to limit EFFD development to the observed latitudinal distribution. 


\section{INFLUENCE OF CRATER MORPHOLOGY}

\subsection{Introduction}

Craters dominate the morphology of Mars and control the overall topography and stratigraphy of the surrounding area. The cratering record on Mars extends back over 4 billion years due to the lack of plate tectonics recycling the crust and a weak hydrologic cycle. In this environment impact features persist for millennia and cover the landscape. But unlike lunar craters, Martian craters can be highly modified and eroded by fluvial and aeolian processes. Due to EFFDs' strong crater dependence it is important that one understands the location in which they are found. This chapter discusses the unique stratigraphy that craters produce and the importance that the crater rim has on EFFD distribution and morphology.

\subsection{Background}

\subsubsection{Crater Formation}

Melosh 1989 describes the formation of craters begining with the impact event. This impact creates a crater not only by excavation and depression of material from the center but also by pushing and uplifting the outer rim. The elevation of the rim is approximately half from basal rock uplift and the rest is ejecta. These two rock types are both highly fractured and broken with multiple and extensive faults running through them as well as brecciated material. The shock wave from the impact event is quite extensive and blows material well out of the cratering zone. As the distance from the crater increases, less material is transported and deposited, and fragments sizes become smaller. The importance of water in crater morphology is quite extensive and many Martian craters show evidence of fluidized ejecta which most researchers believe are the result of impacts into water rich locations. Fluidized ejecta 
incorporate water into the ejecta of a crater and cover the landscape like a blanket creating a hummocky terrain which will have localized depressions. The energy from the impact is quite large and melts the local rock but the energy is quickly dissipated and models show that an impact into ice rich material cannot melt enough ice to create fluidized ejecta.

The stratigraphy near the crater rim has a very unique layering of overturned material. During the excavation stage of crater formation, the explosive force of crater ejecta is known to overturn the surficial layers just exterior to the crater rim. This folding lays inverted stratigraphic layers right on the crater rim over top of the original stratigraphy creating a sandwich type layering. Though broken and fractured this stratigraphy is relatively consistent and intact [Melosh 1989].

Related to this inversion is the emplacement of secondary craters and material from the ballistic emplacement of material excavated from the crater. These projectiles act like mini meteor strikes that occur across the landscape. Unlike typical craters which are circular and deep, secondary ejecta can often be elongated and relatively shallow, typically occurring in groupings and with an obvious radial pattern from the source of impact. Larger secondary blocks are often found close to a crater rim and can create a rugged terrain.

\subsubsection{Crater Modification}

After the initial impact and creation of craters, the weathering and erosional forces start to modify the crater morphology in distinct ways. On airless bodies like the Moon, modification is limited to gravity driven processes like slumping while on Earth every surfical process is drowned out by fluvial erosion. On Mars gravity, water, and atomspheric processes operate at similar rates and produce unique crater-forms. Erosion rates across the planet vary depending on elevation, latitude, age and environment but crater Noachian erosion rates related to early 
fluvial erosion in the highlands are thought to be around $0.0004 \mathrm{~mm} / \mathrm{yr}$. Erosion tends to backwaste the craters over time, enlarging their diameter between 10-30\% [Craddock and Howard 1997]. As the craters progress in their degradation, a number of morphological traits tend to change. First, the craters rim height degrades quickly progressing until the elevational relief is minimal and form a "cookie cutter" appearance with the rim flattened and rounded. The second morphological change is that these crater depressions change from a rounded bowl shape to a flat floor as material is deposited inside the crater filling the bottom with significant amounts of material with some craters known to be completely infilled. The third morphological change is that the crater slopes become less steep both on the interior and exterior as the crater rims erode and material is transported down slope [Craddock and Howard 1997]. But since the Hesperian, fluvial erosion on Mars has been limited and most modification observed is aeolian in nature [Greeley 1992].

\subsection{Observed Characteristics}

I measured many of the physical characteristics of the craters on which EFFDs were situated. By examining the radius of the crater, crater type, distance from the crater rim, and EFFD location on the crater rim, I hope to gain an understanding of what locations and processes favor EFFD development.

Radius:

The radius of the crater was measured on THEMIS mosaic and Viking images. Even though there are some distortion errors in the images, the measurement of crater size is crude enough that a standard $233 \mathrm{~m} /$ pixel was used for all Viking images to give a rough estimate of the size of the craters. 


\section{Crater type:}

Craters in the Southern Highlands have a number of different morphologies reflecting both a range of ages and varying influence of water-related processes. As EFFDs appear to be late stage developments on the landscape, crater morphology and degradation are important as the backdrop on which these features are formed. The type of crater was categorized as one of three crater types based on composite THEMIS images. The first category of crater identified was fluidized ejecta craters. These craters are characterized by a lobate form of one or more sheets of material that appears to have been emplaced by fluidization processes (Figure 11a) [Barlow et. al. 2000]. These craters typically have smooth crater rims and uniform, smooth ejecta patterns. Fluidized ejecta indicate that a large amount of liquid was incorporated into the ejecta.
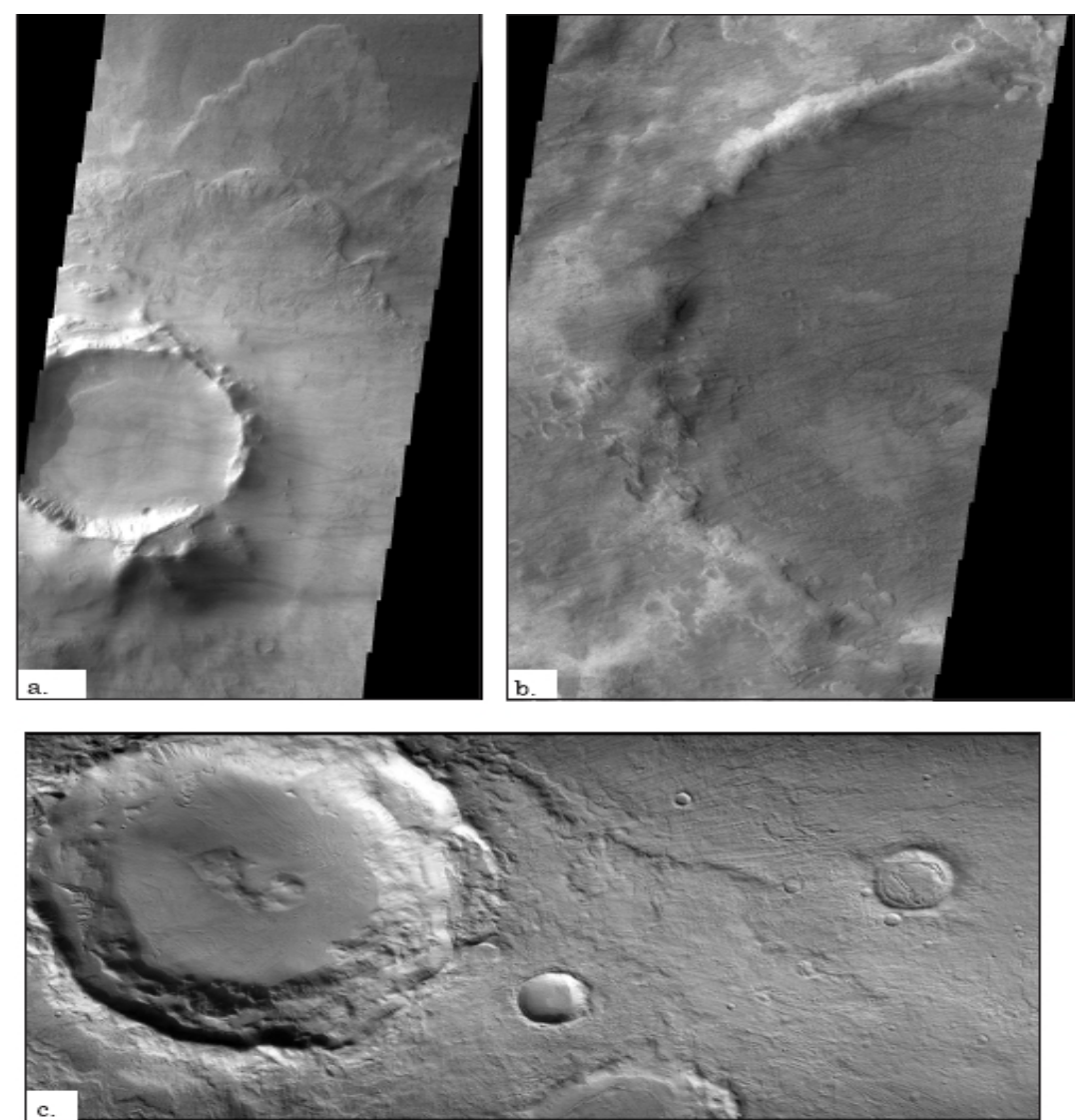

Figure 11: Crater types. (a.) Fluidized (THEMIS V10357007). (b.) Radial type ejecta (CTX P030021871405). (c.) degraded (THEMIS V16738009). 
The second type of crater morphology identified were radial ejecta craters, which are similar to lunar crater types, appearing to be emplaced by material traveling ballistically from the impact location. Craters typically have a highly irregular rim and an undulating, irregular ejecta pattern (Figure 11c) and represent younger craters formed without water present during emplacement.

The third type of crater identified was highly eroded craters which have a highly degraded morphological structure and significant infilling (Figure 11b). These craters are significantly older and have had large amounts of material removed from their crater rims

Distance from the crater rim apex:

It was noticed early in the survey that there was a strong association of EFFDs with the crater rim. A measurement was taken to determine the distance of EFFDs from the crater rim apex. Measurements were taken of the shortest distance between EFFDs and the nearest rim apex.

Orientation of the EFFD:

Since EFFDs are elliptical, the axial orientation of the EFFDs in planform was measured in Photoshop. The major axis of the EFFD was measured at the EFFD's largest diameter location and the minor axis was measured at the widest location 90 degrees from the major axis. Though measurements were taken to one degree's worth of precision I believe that the accuracy is likely $+/-5$ degrees due to difficulty identifying the center line. 
Aspect Relative to the Crater:

To determine whether there was any pattern to the spatial distribution of EFFDs relative to the crater, the position of EFFDs on the crater was measured relative to north determined using a combination of primary, context, and regional images. All images used were geo-rectified before measurements were made and when possible direct measurements were used though some cases required that the angle was estimated to the nearest 10 degrees.

\subsection{Results}

\subsubsection{Distance from the Rim}

The distance from the crater rim crest varies from $8000 \mathrm{~m}$ outside the rim to $6000 \mathrm{~m}$ inside the rim with $74 \%$ of EFFDs located within 1000 m of the rim and $45 \%$ within 200 meters. EFFDs show no significant preference for the inner crater wall or the outer crater (Figure 12).

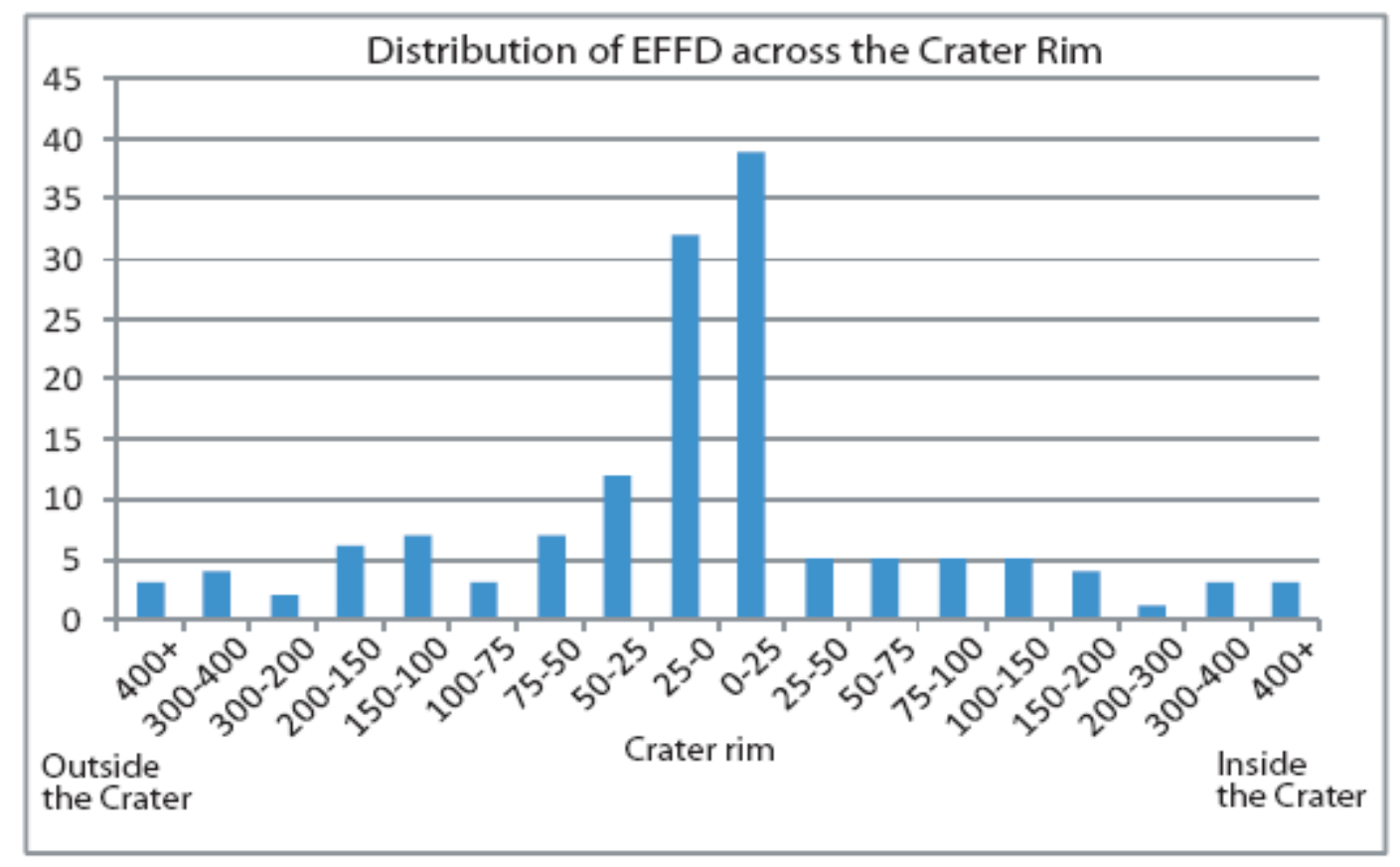

Figure 12: EFFD distribution across the crater showing no preference for the inner or outer side of craters. 


\subsubsection{Crater Size}

Crater sizes range from $6 \mathrm{~km}$ to $170 \mathrm{~km}$ in radius and EFFDs are concentrated on craters in the $40 \mathrm{~km}$ to $70 \mathrm{~km}$ range. Larger craters interestingly do not have a higher occurrence of clustering or interconnected EFFDs but the size of the crater does increase the distance EFFDs are found from the crater rim with $>50 \mathrm{~km}$ craters having rim to EFFDs distance jumping from $96 \mathrm{~m}$ to $150 \mathrm{~m}$ on average and the range extending from $\sim 200 \mathrm{~m}$ to $1500 \mathrm{~m}$.

\subsubsection{Crater Type}

The craters types were comprised of $16 \%$ fluidized ejecta, $39 \%$ non fluidized ejecta, and $45 \%$ heavily degraded craters. I found interconnected terrains to be less frequent in non fluidized ejecta craters with only $8 \%$ of these craters containing interconnected crater types compared to $\sim 25 \%$ in the other two landscapes.

\subsubsection{Axial Orientation}

The orientations of EFFDs' major axis were found to be orientated tangential to the crater rim. Orientation measurements were made of both the EFFDs' locations on the rim as well as the major axis of the EFFD. Theses orientations are not correlated with regional distribution or

with nearby features, but a strong relationship emerged between EFFD orientation and location relative to the rim crest. These measurements were combined and expressed as the angle away from the tangent to the crater rim. This gave a measurement ranging from 0 (orientated perpendicular to the crater rim) to 90 (tangential to the crater rim) (Figure 13). The preference towards being tangential is quite strong with $55 \%$ of EFFDs orientated between $0-20$ degrees of tangential and the distribution exponentially decreases with distance from the rim crest. This preference was seen in all EFFDs and crater types and regional features. 

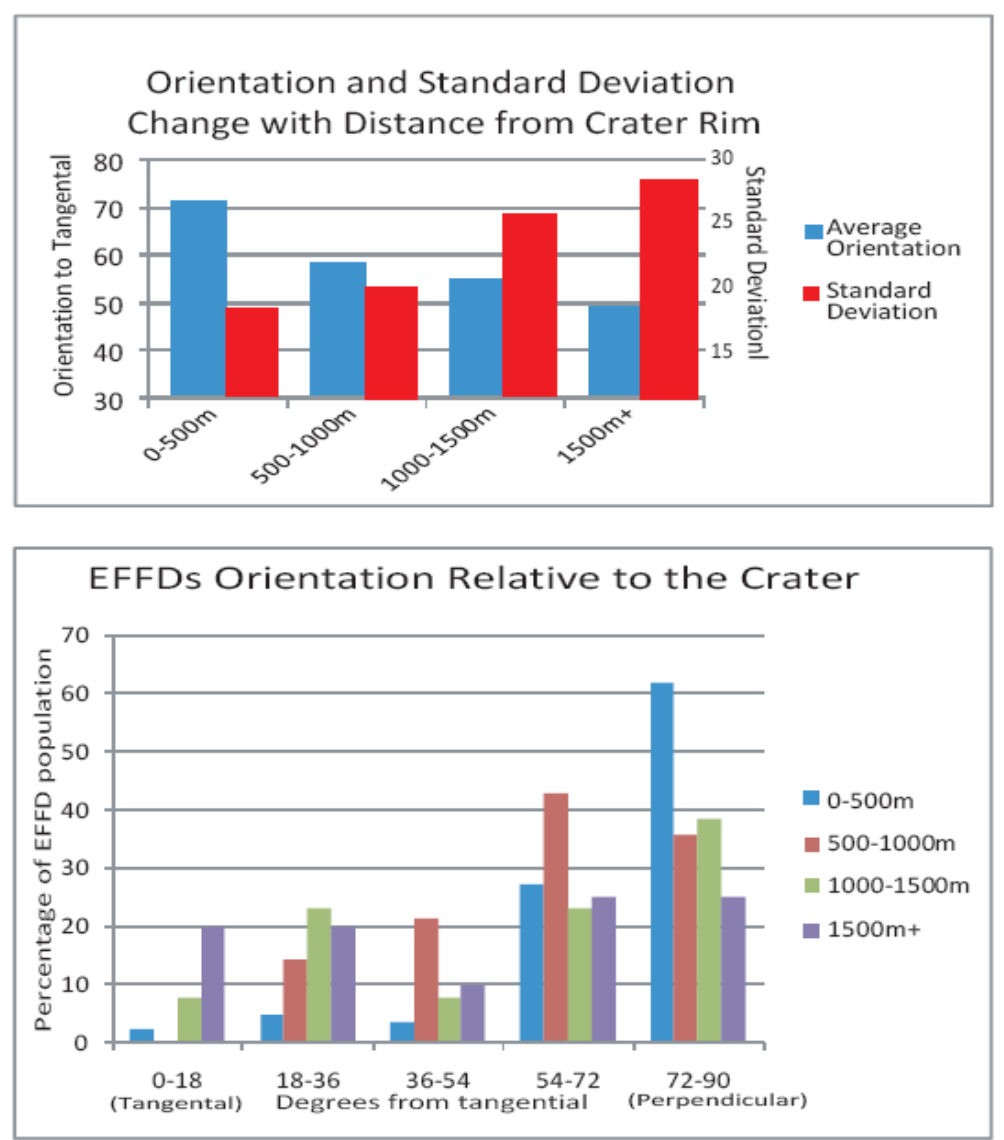

Figure 13: Distance from the crater rim's influence on orientation. Showing a strong tendency for EFFDs near the rim to be tangential and EFFDs further away to have no orientational preference.

Distance from the crater rim apex was observed to influence the orientational preference of EFFDs (Figure 13). When the data was binned into $0-500 \mathrm{~m}, 500-1000 \mathrm{~m}, 1000-$ $1500 \mathrm{~m}$, and $1500 \mathrm{~m}+$ groups it was found that the orientation patterns shifted greatly both in their mean and the standard deviations. The $0-500 \mathrm{~m}$ group was found to have orientations averaging 71 degrees with a standard deviation of 18.1 showing a clear preference for more tangential orientations. These numbers quickly fell as the distance from the rim increased and when compared to the over $1500 \mathrm{~m}$ group we find that the mean orientation is almost in the center at 49 degrees with a much larger standard deviation of 28 . With the whole data range within 2 standard deviations of the mean these can be considered random. An $\mathrm{F}$ test examining the similarity of these two data sets showed that natural variations could not explain this difference $(<0.3 \%)$. In addition, there is a uniform increase in the EFFDs with more tangential 
orientations in the $<1000 m$ groups, while the distribution of the more distal group becomes more randomly distributed.

\subsection{Discussion}

\subsubsection{Crater Rims}

So what exactly could crater rims have that would create such a strong orientational and locational control? I believe that it is their local elevation. Global elevation was shown not to have a significant impact on EFFD distribution; however, that measurement does not address relative elevation. Most of the topography in the Martian Highlands is dominated by craters and the steep crater rim peaks. These local maxima on crater rims are areas of high erosion due to the steep gradient promoting gravity driven processes, the lack of sediment input from higher elevations and increased exposure to the wind (Figure 14). These processes in themselves only remove very small amounts of material and operate on a large scale but I believe that this elevationally controlled erosion removes a protective surface layer allowing subsequent sublimation of underlying volatile-rich deposits. Similar processes happen on Earth where thermokarst depressions are dependent on some erosional mechanism to remove both the armoring surface as well as material produced by melting and sublimation [Washburn 1989]. I propose that this enhanced erosion from elevation is the triggering mechanism for sublimation as the increased erosion rates near crater rims removes a protective surface layer over a volatile rich unit which then is able to sublimate away. This process would account for the observed trends in EFFD morphology and placement. The rapid decrease in occurrence rates with distance from the crater apex would be the result of being located further downslope where lower erosion rate would leave the protective layer intact. The change in orientation downslope would 
also be accounted for by this general erosional prospective. The areas of highest erosion rates will preferentially follow the top of the crater rim creating orientations that follow the crater rim.
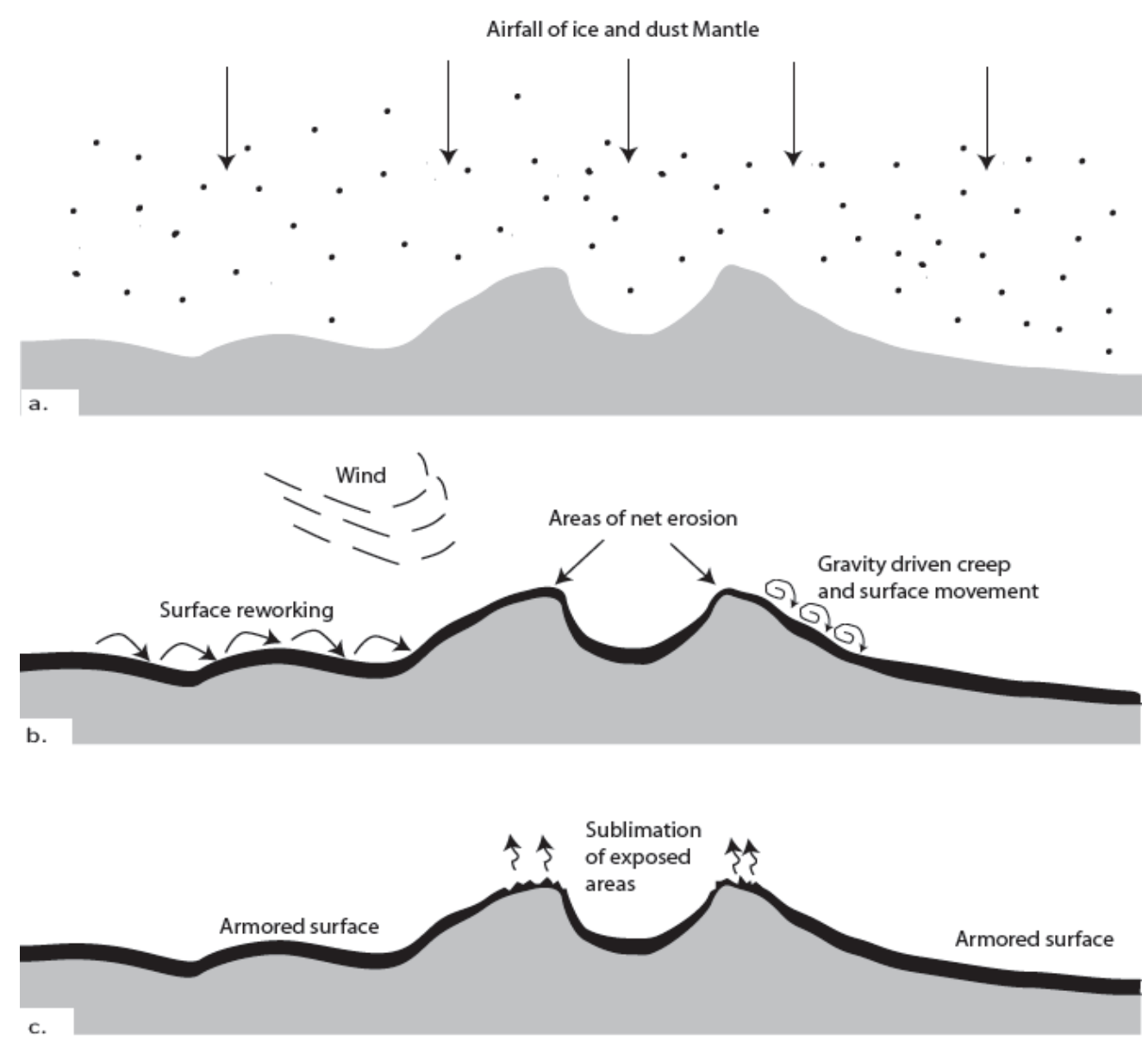

Figure 14: Conceptual model of EFFD development on craters. (a.) Air fall deposition of an ice/dust mantle unit. (b.) High erosion at local elevation maxima relative to the rest of the landscape remove the armored surface. (c.) The degradation and sublimation forming EFFDs.

So even though the volatile-rich subsurface material is likely related to a mantling unit and is extensive, the locations where subsidence will occur are restricted to a strip running tangential to the crater rim and hence the resulting depressions will follow this window. With increased distance from the crater rim, the elevation controlled erosional stops dominating the erosion rates of the area and other localized factors come into play, explaining not only the decrease in occurrence rates of EFFDs downslope that is observed, but also the shift of orientations away from being crater dependent. With elevation-related process not dominating 
erosion rates, other localized processes such as landslides, faults, locally weak or unconsolidated material, micrometeoritic and secondary impacts would share a role in where erosion could expose the subsurface volatiles and one would not expect to observe any pattern in the distribution or orientation of these EFFDs. The influence of crater size would also suggest that local elevation plays a role. Larger craters will produce higher crater rims which would intensify the erosional process and extend the area which is susceptible to the elevation erosional mechanism and hence where EFFDs are found.

\subsubsection{Other Crater Properties}

In examining the broad distinct properties of crater rims including morphology, historical erosion, ejecta material I found variations had little influence on EFFDs. This suggests that EFFDs are not dependent on the local crater material or stratigraphy. It is important to note that not all craters have EFFDs on them. In fact, only a relatively small percentage of craters spanning a significant range of types, erosional states, and not regionally clumped. I believe that this indicates that the emplaced crater stratigraphy and material is likely highly variable and therefore not significant in EFFD development. This idea is supported by the observation that EFFDs appear to be shallow modification feature on the landscape with no relationship to the level of degradation of the crater. Erosion would likely expose multiple strata ranging from a thin ash covering layer to coarse ejecta material to Noachian fluvial deposits. The preference I

observed for slightly degraded craters to contain fewer interconnected EFFDs is likely a sampling problem as the degradation of a crater was based on physical appearance rather than a more definitive rim height vs. crater width ratio [Forsberg-Taylor et. al. 2004] which would lead to the tendency to mistakenly classify dissected rims into the category of degraded craters. 
This independence from both material and degradational state leads me to conclude that EFFDs are extremely young features not related to either crater formational processes and material nor Noachian fluvial conditions. The variation in crater age, degradation, as well as the wide spatial distribution of EFFD across the globes suggests that they are not dependent on some local climatic condition unique to a certain area or crater emplacement time but rather are dependent on latitude. This leads me to believe that EFFDs are near surface features which are process controlled and influenced primarily by the local elevation maxima related to crater rims. EFFDs' strong correlation to a crater rim indicates that the process is likely driven by some local morphological condition such as elevationally controlled erosion. A regional scale process would produce either a random orientations or create a regional orientation across the entire crater rather than the distinctive clustering we see at the top of the rim.

Hence, I believe elevationally controlled erosion is the only process that accounts for all of the observed regional and crater related distributions and must play a role, along with latitudinally controlled ice, in creating EFFDs. 


\section{CONCLUSIONS AND HYPOTHESES}

\subsection{Introduction}

Our survey was able to identify 183 craters containing EFFDs. We found that the depressions are approximately $20 \mathrm{~m}$ deep and $1000 \mathrm{~m}$ in diameter, are situated near the apex of the crater rim, and appear to be erosion features in the landscape. EFFDs also display a tendency to orientate themselves to be tangential to the crater rim which we interpret to be a result of locally enhanced erosion on the crater rim. There is a strong correlation of latitude with the EFFDs concentrated around $40^{\circ}$ latitude and a strong relationship with the mantling units and other periglacial features found in these areas. We believe that these characteristics indicate that EFFDs are periglacial features.

In this chapter I review the observations that were made and the conclusions that were drawn from them. I then evaluate some alternative hypotheses and mechanisms that can account for these observed features and trends and then explore proposed mechanisms for EFFD development.

\subsection{The Role of Ice}

A number of different processes on Mars are capable of forming depressions into preexisting terrain. In examining EFFD morphology and their regional relationships, most characteristics point to some sort of periglacial or ice related process rather than fluvial, volcanic, tectonic or aeolian processes. The basic morphology of an enclosed depression indicates that there was a large volume of material displaced or removed and no visible surficial outlet for fluid or gravity driven processes. This leaves ice sublimation and aeolian erosion as the two most likely candidates which can create these depressions. Though aeolian processes are 
always present and I believe they play a role in EFFD formation, the lack of significant proximal wind erosional features such as yardangs and dunes along with the non-regional orientation pattern of EFFDs indicate that wind erosion alone is not the growth mechanism of EFFDs. Ice, on the other hand, seems to have a strong correlation to EFFDs with a strong periglacial latitudinal banding, observed proximal periglacial features, and a sharp thermokarst-like EFFD morphology. The presence of a mantled unit offers both a mechanism for the accumulation of ice to these elevated terrains as well as an ideal medium for sublimation to occur within.

\subsection{The Role of Elevation}

Local elevation highpoints seem to be the triggering mechanism for EFFD development. It was observed that many of the strong correlations of EFFDs were tied to the location of the craters rim with $75 \%$ of EFFDs located within $1000 \mathrm{~m}$ of the apex of crater rims and none found on the intercrater plain. In addition, the observed orientational preference towards a tangential relationship to the crater rim disappeared with distance from the crater rim. Though crater rims have a number of unique morphological and stratigraphical properties which could initiate erosion, most are not capable of producing sharply defined small scale features at the surface and the wide range of crater types make the underlying stratigraphy a highly variable property. The main property that craters of various age, size, and type share is the high local relief. I suggest that this elevation provides enhanced erosion in the landscape which triggers EFFD by encouraging exposure of subsurface volatile-rich material.

\subsection{Possible Formation Mechanisms}

Though many features on Mars have been identified as thermokarst features, I believe that the unique characteristics of EFFDs indicate that their formation requires a separate 
formation model. Here I examine different mechanisms which can account for the observed features and discuss their merits.

\subsubsection{Prior Ice Emplacement}

The most uncertain observational correlation made was the relationship between EFFDs and the mantled terrain as some locations had no directly observed mantle. One of the reasons for proposing EFFD development through erosion into a mantle unit is that it addresses the problem of getting water or ice to these high locations. An alternative solution not involving volatile input from the mantle unit is that water was emplaced during the cratering event. Cratering models show impact events produce an overturning and inversion of the surface layer near the crater rim [Melosh 1989]. Additionally, the heat and pressure waves produced by impacts are well below the energy levels needed to melt ice at the distance of the crater rim and so would produce an omelet-style stratigraphy with the surface layer trapped in the middle. Any subsurface ice or volatile rich near surface unit would remain intact and be protected from sublimation by the overlying material. In this scenario, as the rim begins to erode down the icerich deposits would be exposed and begin to sublimate away. As the overlying material would likely be volatile free there would be no gradual downwasting but rather a surface collapse.

I believe that this scenario is unlikely based primarily on the morphology of the EFFDs and their global distribution. If subterranean ice were the cause EFFDs would be much more chaotic in shape. Even with high infilling rates this would not create uniformly flat floors. One would expect to see EFFDs depths ranging from a couple meters to hundreds of meters in depth as the thickness of volatile rich material would vary greatly and not have the observed floor uniformed flatness. Most importantly, a purely subsurface volatile material explanation would make it difficult to explain the tight latitudinal control and the apparent similarity in age of 
formation. With climatic conditions on Mars being highly variable over geologic time spans, ice and water rich soils would have been present in many locations both temporally and spatially and would produce EFFD features that would not be limited so tightly limited to a latitudinal band. This would produce not only a planet wide spatial distribution but, as this process would operate over large time spans, but we would expect to see many features in varying states of degradation as steep scarps would be unlikely to persist over long time periods.

\subsubsection{Scalloped Terrain}

Another possibility is that EFFDs could be related to scalloped depressions resulting from solar induced sublimation of the mantled units. Scallops are observed in heavily mantled areas near the polarward latitude limits of EFFDs and these could just be an expression of this mechanism at lower latitudes in thinner mantled units. EFFDs' flat floor morphology with a sharp basal slope contact could be explained as representing the underlying bed rock limiting the further subsidence as the overlying material has been totally sublimated away. The sharp sidewalls and sharp top transitions into the scarp could then be due to backwasting as EFFDs grew. However there are a couple of serious concerns about lumping EFFDs as a subset of scalloped depressions. The first difficulty is that the difference in morphology extends beyond the presence of flat floors. Scalloped depressions have asymmetric sides and a "scalloped" or scoop shape due to their down wasting from the surface which is produced as material slowly is removed from the surface [Morgenstern et. al. 2007]. Even if we assume that at some point backwasting overtakes solar heating or downwasting reaches bedrock to produce the steep slopes and flat floors of EFFDs, one would still expect to see transitional EFFDs in the region that are smaller in size but still retain the scalloped shape and asymmetric slopes. 
The second difficulty with solar radiation as the mechanism of EFFD growth is the distribution of EFFDs on the crater. If we assume that both elevation-controlled erosion of a protective layer and solar radiation control the distribution of EFFDs we would expect clustering on equator facing slopes in response to the higher radiation at these locations. Similarly the observed decrease of orientation preference of EFFDs down slope cannot be explained by solar heating as orientations would align to catch the direction of maximum solar radiation.

\subsubsection{Elevationally Triggered Sublimation}

So if solar radiation and gradual backwasting or down-wasting processes are not responsible for EFFDs, what is? In section 3 we noted the similarity of the morphologies of EFFDs to that of terrestrial karst and subsidence features. Yet the location of EFFDs on the top of mountains and the thin atmosphere make the development of any thermal pulse into the subsurface not related to direct solar radiation difficult. Exposure to the atmosphere from erosional stripping is the most likely scenario which accounts for the locations on crater rims. I believe that a crust or armored thin surface over a volatile rich deposit can best explain the observed trends of EFFDs. A process similar to alases on Earth is the best analog to the process we observe on Mars.

Alases are thermokarst depressions similar in size and depth to EFFDs and are caused by the melting of permafrost layers and are commonly found in Siberia, Alaska and northern Canada. Genesis of these is thought to result from the decay of permafrost where multiple collapse features from melting ice wedges coalesce into a large circular or oval depression. The soil's ice cementation melts creating an unconsolidated sediment which internal fluvial action spreads around creating an undulating but relatively flat bottom and surrounded by a steep scarps. [Czudek and Demek 1970]. 
EFFDs similar morphology to alases is quite striking but due to their location and inferred young age fluvial action is unlikely. I believe though that wind, on a long enough time scale, can act as the mobilizing mechanism. I have already stated that elevated craters are areas of relatively high aeolian erosion and that the mantle deposit, which is the unit into which EFFDs are eroded, is composed of a fine grain dust and ice mixture. Aeolian erosion of the crater rim removes or breaks through a thin armored top layer exposing the underlying ice cemented dust which sublimates away and uncements the dust. Areas of high aeolian erosion will expose multiple locations where this process can occur and quickly grow and coalesce together forming interconnected terrain.

Though there is significant volume loss from just volatile sublimation, a main concern with this idea is that the dust lag which would form would protect against growth of these features. But, just as scalloped depressions are capable of removing this material, EFFDs likely have it removed by wind as the ash size particles are easily transported by suspension and contain few particles large enough to be limited to saltation and thereby remain in the depression. The depth of these deposits are then controlled by either a deflation lag or more likely by bedrock or a volatile poor layer.

The distribution of EFFDs upon the crater is also well explained by this hypothesis. The elevation-dependent erosional mechanism still explains the preference of EFFDs near the top of the crater and their orientation tangential to the crater rim. As one descends down the crater, the exposure points where sublimation would occur would become fewer and distributed based on a combination of factors as elevation erosion diminishes and other processes can play a role in expose the subsurface ice. 
Similarly, the wide range of degree of clustering is accounted for by this hypothesis. It was noted that one of the main variations that EFFDs have is their tendency to cluster, which range from solitary features to an interconnected terrain. This pattern is exactly what one would expect in a armored sublimation environment. In some locations, the protective layer would be removed over a large area of the landscape and multiple EFFDs would form creating a generally broken or interconnected landscape. Though the shape and size of these features would be variable it would still be limited to the area of the crater near the apex. Whereas, in low erosional areas and where the protective layer is thick, we would expect only one or two EFFDs would be able to develop.

The main difficulty with this scenario is that I don't see any wind related features in EFFDs. There is no regional axial orientation, no asymmetric scarps or slopes, and no other aeolian features. But I believe that this is due to the unique situation in which EFFDs are formed. Unlike orientated thaw ponds on Earth which are orientated with the wind due to the ability of the wind to churn the water in the depressions, EFFDs did not have liquid water filling them. Since the sublimation would then be a result of atmospheric exposure and not liquid water wind would not play that great of a role past the removal of the armored surface. The coalition of multiple breaks in an armor surface would control the orientation of the depressions and the system would be limited by the rate of sublimation of the cementing material rather than transport limited by the wind. This would explain also explain why there is no asymmetry in the scarps or slope nor loose material on the floor as wind is not able to erode until sublimation occurs and then quickly remove that material. A lack of aeolian feature would also be expected as locations at the top of the crater would be devoid of the amount of sediment necessary to abrade into the surface or create sediment deposits like dunes. 


\subsection{Implications on Martian Research}

The implication of EFFDs elevationally controlled sublimation is two fold. The first is it reinforces the evidence of near surface ice deposits and offers a proxy feature for its identification. The second and more important implication of this research is that EFFDs would be indicators of where near surface ice would be nearest to the surface and any protective armoring the thinest. As much of Martian research focuses on the the location and current state of water on the planet. Understanding of the nature of EFFDs could help focus future water related research.

\subsection{Conclusion}

EFFDs were found to have 3 main distinguishing characteristics. First, their morphology consists of a fairly flat and uniform flat floor surrounded by $10-30 \mathrm{~m}$ steep scarps on all side. Second, they are highly dependent on their relationship with crater rims both in spatial distribution and with their axial orientation being tangential to rim. Finally, I observed a strong latitudinal dependence restricting EFFDs to the mid-latitudes between $30^{\circ}$ and $65^{\circ}$. These characteristics are in line with other periglacial features found both on Mars and on Earth. I believe that these features represent sublimation pits similar to alases on Earth where a protective top layer is removed from high exposed locations exposing a volatile rich unit below which sublimates away.

\subsection{Future Work}

This project was designed to investigate many of the physical properties of EFFDs but at the time of development the importance of the mantle unit, ice and the role of wind was not fully appreciated. Our investigation suggests that wind plays a role in EFFD development but it is hard to determine how significant a role. To investigate this feature further incorporating 
atmospheric data such as wind strength and its influence on occurrence rates and interconnected EFFD type would help determine if wind is an important factor in removing the armored surface or if it is controlled by gravity driven creep. 


\section{Works Cited}

Ansan, V., Mangold, N., 2006. New observations of Warrego Valles, Mars: Evidence for precipitation and surface runoff Planetary and Space Science, 54.

Baker, V.R., 1992. Channels and valley networks. in Mars, pp. 493-522, ed. Kieffer, H. H. The University of Arizona Press, Tucson.

Barlow, J.B., FM Costard, RA Craddock, JB 2000. Standardizing the nomenclature of Martian impact crater ejecta morphologies, Journal of Geophysical Research, 105.

Bourke, M.C., Edgett, K.S. \& Cantor, B.A., 2008. Recent aeolian dune change on Mars, Geomorphology, 94, 247-255.

Boynton, W.V.F., W. C. Squyres, S. W. Prettyman, T. H.; Bruckner, J. Evans, L. G. Reedy, R. C. Starr, R. Arnold, J. R.; Drake, D. M., 2002. Distribution of hydrogen in the near surface of Mars: evidence for subsurface ice deposits, SCIENCE, 81-84.

Byrne, S. \& Ingersoll, A.P., 2003. A Sublimation Model for Martian South Polar Ice Features, SCIENCE, 299, 1051-1053.

Caprarelli, G., Pondrelli, M., Di Lorenzo, S., Marinangeli, L., Ori, G.G., Greeley, R. \& Neukum, G., 2007. A description of surface features in north Tyrrhena Terra, Mars: Evidence for extension and lava flooding, Icarus, 191, 524-544.

Chamberlain M.A., B.W.V., 2007. Response of Martian ground ice to orbit-induced climate change, Journal of Geophysical Research E: Planets, 112.

Cord, A., Baratoux, D., Mangold, N., Martin, P., Pinet, P., Greeley, R., Costard, F., Masson, P., Foing, B. \& Neukum, G., 2007. Surface roughness and geological mapping at subhectometer scale from the High Resolution Stereo Camera onboard Mars Express, Icarus, 191, 38-51.

Costard, F. \& Baker, V.R., 2001. Thermokarst landforms and processes in Ares Vallis, Mars, Geomorphology, 37, 289-301.

Costard, F.F., F. Mangold, N. Peulvast, J. P. , 2002. Formation of Recent Martian Debris Flows by Melting of Near-Surface Ground Ice at High Obliquity, SCIENCE, 110-112.

Craddock, R.A., Maxwell, T. Howard, Alan D., 1997. Journal of Geophysical Research, 102, 13,321313,340.

Craddock, R.A.H., Alan D., 2002. The case for rainfall on a warm, wet early Mars, Journal of Geophysical Research, 107, 36.

Czudek, T. \& Demek, J., 1970. Thermokarst in Siberia and its influence on the development of lowland relief, Quaternary Research, 1, 103-120.

Dickson, J. L., et al., 2007. Martian gullies in the southern mid-latitudes of Mars: Evidence for climate-controlled formation of young fluvial features based upon local and global topography. Icarus. 188, 315-323.

Fanale, F.P., 1992. Mars: Epochal Climate Change and Volatile History. in Mars, pp. 1135-1179, ed. Kieffer, H. H. The University of Arizona Press, Tucson.

Fanale, F.P., Salvail, J.R., Zent, A.P. \& Postawko, S.E., 1986. Global distribution and migration of subsurface ice on mars, Icarus, 67, 1-18.

Fassett, H., J., 2008. Valley network-fed, open-basin lakes on Mars: Distribution and implications for Noachian surface and subsurface hydrology Icarus, 198.

Forget, F.H., R. M. Montmessin, F. Levrard, B. Head, J. W. , 2006. Formation of Glaciers on Mars by Atmospheric Precipitation at High Obliquity, SCIENCE, 311, 368-370.

Forsberg-Taylor, J., AD Howard, RA Craddock, 2004. Crater degradation in the Martian highlands: Morphometric analysis of the Sinus Sabaeus region and simulation modeling suggest fluvial processes, Journal of Geophysical Research, 109. 
Goldspiel, J., SW Squyres, 1991. Ancient aqueous sedimentation on Mars, Icarus, 89, 392-410.

Golombek, M.B., N., 1999. Erosion Rates on Mars and Implications for Climate Change: Constraints From the Pathfinder Landing Site, Journal of Geophysical Research, 105.

Greeley, R., 1992. Martian aeolian processes, sediments, and features. in Mars, pp. 730-766, ed. Kieffer, H. H. The University of Arizona Press, Tucson.

Gulick, V., 2001. Origin of the valley networks on Mars: a hydrological perspective, Geomorphology, 37.

Haberle, R.M., Murphy, J.R. \& Schaeffer, J., 2003. Orbital change experiments with a Mars general circulation model. in Icarus, pp. 66(24).

Hartmann, W., G Neukum, 2001. Cratering chronology and the evolution of Mars, Space Science Reviews, 96.

Head J.W., F.C.I., Kreslavsky M.A., Marchant D.R., \& Agnew M.C, 2006. Extensive valley glacier deposits in the northern mid-latitudes of Mars: Evidence for Late Amazonian obliquitydriven climate change, Earth and Planetary Science Letters, 241, 663-671.

Head, J.W., Hiesinger, H., Masson, P., Kreslavsky, M., Milkovich, S., Jaumann, R., Neukum, G., Carr, M., Hauber, E., Hoffmann, H., Foing, B., Werner, S. \& van Gasselt, S., 2005. Tropical to mid-latitude snow and ice accumulation, flow and glaciation on Mars. in Nature, pp. 346(346).

Head, J.W., Mustard, J.F., Kreslavsky, M.A., Milliken, R.E. \& Marchant, D.R., 2003. Recent ice ages on Mars. in Nature, pp. 797(796).

Hecht, M.H., 2002. Metastability of Liquid Water on Mars, Icarus, 156, 373-386.

Heldmann, J.L., Carlsson, E., Johansson, H., Mellon, M.T. \& Toon, O.B., 2007. Observations of martian gullies and constraints on potential formation mechanisms: II. The northern hemisphere, Icarus, 188, 324-344.

Howard, A., Moore, J., Irwin, R., 2005. An intense terminal epoch of widespread fluvial activity on early

Mars: 1. Valley network incision and associated deposits, Journal of Geophysical Research, 110.

Hynek, B.M. \& Phillips, R.J., 2001. Evidence for extensive denudation of the Martian highlands. in Geology, pp. 407.

Irwin, R., Maxwell, T., Howard, A., Craddock, R., Leverington, D., 2002. A large paleolake basin at the head of Ma'adim Vallis, Mars, SCIENCE, 296.

Kadish, J.H., NG Barlow, DR Marchant, 2008. Martian pedestal craters: Marginal sublimation pits implicate a climate-related formation mechanism, Geophysical Research Letters, 35.

Kasting, J., 1991. CO2 condensation and the climate of early mars, Icarus, 94.

Kreslavsky, J.H., 2000. Kilometer-scale roughness of Mars- Results from MOLA data analysis, Journal of Geophysical Research, 105, 695-626.

Laskar J., A.C.M.C., M. Gastineaua, F. Joutela, B. Levrarda and P. Robutela, 2004. Long term evolution and chaotic diffusion of the insolation quantities of Mars Icarus, 2004, 343364.

Levrard, B., Forget, F., Montmessin, F. \& Laskar, J., 2004. Recent ice-rich deposits formed at high latitudes on Mars by sublimation of unstable equatorial ice during low obliquity. in Nature, pp. 1072(1074).

Li, H., Robinson, M.S. \& Jurdy, D.M., 2005. Origin of martian northern hemisphere mid-latitude lobate debris aprons, Icarus, pp. 382(313).

Mahaney, W.C., Miyamoto, H., Dohm, J.M., Baker, V.R., Cabrol, N.A., Grin, E.A. \& Berman, D.C., 2007. Rock glaciers on Mars: Earth-based clues to Mars' recent paleoclimatic history, Planetary and Space Science, 55, 181-192. 
Marchant, D.R. \& Head lii, J.W., 2007. Antarctic dry valleys: Microclimate zonation, variable geomorphic processes, and implications for assessing climate change on Mars, Icarus, 192, 187-222.

Mellon, M.T., Phillips, RJ, 2001. Recent gullies on Mars and the source of liquid water, Journal of Geophysical Research, 106, 1-15.

Mellon, M.T., Feldman, W.C. \& Prettyman, T.H., 2004. The presence and stability of ground ice in the southern hemisphere of Mars, Icarus, 169, 324-340.

Melosh, H.J., 1989. Imact Cratering, edn, Vol., pp. Pages, Oxford University Press, New York.

Milliken, R.E., J.F. Mustard, and D. L. Goldsby (2003), Viscous flow features on the surface of Mars: Observations from high-resolution Mars Orbiter Camera (MOC) images, J. Geophys. Res., 108

Mischna, M.A.R., M.I; Wilson, R.J.; McCleese, D.J, 2003. On the orbital forcing of Martian water and $\mathrm{CO} 2$ cycles: A general circulation model study with simplified volatile schemes, Journal of Geophysical Research E: Planets, 108, 16-25.

Moore, J., Howard, A., WE Dietrich, PM Schenk, 2003. Martian layered fluvial deposits: Implications for Noachian climate scenarios, Geophysical Research Letters, 30.

Moore, J., AD Howard, 2005. Large alluvial fans on Mars, Journal of Geophysical Research, 110.

Morgenstern, A.H., E. Reiss, D. van Gasselt, S. Grosse, G. Schirrmeister, L. , 2007. Deposition and degradation of a volatile-rich layer in Utopia Planitia and implications for climate history on Mars, JOURNAL OF GEOPHYSICAL RESEARCH, 112.

Mustard, J.F., Cooper, C.D. \& Rifkin, M.K., 2001. Evidence for recent climate change on Mars from the identification of youthful near-surface ground ice, 412, 411-414.

Owen, T., 1992. The composition and early history of the atmosphere of Mars. in Mars, pp. 818835, ed. Kieffer, H. H. The University of Arizona Press, Tucson.

Page, D.P., 2007. Recent low-latitude freeze-thaw on Mars. Icarus, pp. 83(35).

Page, D.R. \& Murray, J.B., 2006. Stratigraphical and morphological evidence for pingo genesis in the Cerberus plains. Icarus, pp. 46(49).

Pondrelli, M., AP Rossi, L Marinangeli, E Hauber, K, 2008. Evolution and depositional environments of the Eberswalde fan delta, Mars, Icarus, 197, 429-451.

Quantin, C., P. Allemand, N. Mangold, G. Dromart, and C. Delacourt, 2005. Fluvial and lacustrine activity on layered deposits in Melas Chasma, Valles Marineris, Mars, Journal of Geophysical Research, 110.

Rossbacher, L.A. \& Judson, S., 1981. Ground ice on Mars: Inventory, distribution, and resulting landforms, Icarus, 45, 39-59.

Schon, J.H., C Fassett, 2008. Multiple Episodes of Recent Gully Activity Indicated by Gully Fan Stratigraphy in Eastern Promethei Terra, Mars, European Planetary Science Congress, 3.

Schorghofer, N. \& Edgett, K.S., 2006. Seasonal surface frost at low latitudes on Mars, Icarus, 180, 321-334.

Sharp, R.P., 1973. Mars: Fretted and Chaotic Terrains, Journal of Geophysical Research, 78, $4073-$ 4083.

Shean, J.H.I., JL Fastook, DR Marchant, 2007. Recent glaciation at high elevations on Arsia Mons, Mars: Implications for the formation and evolution of large tropical mountain glaciers, Journal of Geophysical Research, 112.

Soare, G.O., CL Roehm, 2008. Thermokarst lakes and ponds on Mars in the very recent (late Amazonian) past, Earth and Planetary Science Letters, 272.

Soare, R.J., Kargel, J.S., Osinski, G.R. \& Costard, F., 2007. Thermokarst processes and the origin of crater-rim gullies in Utopia and western Elysium Planitia. in Icarus $L 2$

Squyres, S.W., 1992. Mars, edn, Vol., pp. Pages, The University of Arizona Press, Tuscon. 
Tanaka, K.L., 2000. Dust and Ice Deposition in the Martian Geologic Record, ICARUS, 144, 254266.

Wade, F.A. \& De Wys, J.N., 1968. Permafrost features on the martian surface, Icarus, 9, 175-185. Washburn, A.L., 1979. Geocryology, 406 edn, Vol., pp. Pages, Fletcher \& Sons Ltd, Norwich.

Zanetti, M.R.H., H. Reiss, D. Hauber, E. Neukum, .G, 2008. Scalloped Depressions in Malea Planum, Southern Hellas Basin, Mars. in LPSC, League City, Tx. 